\title{
DEVELOPMENT OF NUMERICAL MODELS FOR THE PREDICTION OF TEMPERATURE AND SURFACE ROUGHNESS DURING THE MACHINING OPERATION OF TITANIUM ALLOY (Ti6Al4V)
}

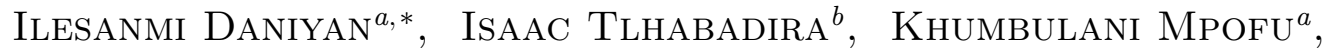 \\ ADEFEMI ADEODU ${ }^{c}$ \\ a Tshwane University of Technology, Department of Industrial Engineering, Pretoria, Staatsartillerie Road, \\ Private Bag X680, Pretoria 0001, South Africa \\ ${ }^{b}$ Tshwane University of Technology, Pretoria, Department of Mechanical \& Automation Engineering, \\ Staatsartillerie Road, Private Bag X680, Pretoria 0001, South Africa \\ ${ }^{c}$ University of South Africa, Department of Mechanical and Industrial Engineering, 1724 Florida Park, \\ Johannesburg, South Africa \\ * corresponding author: afolabiilesanmi@yahoo.com
}

\begin{abstract}
Temperature and surface roughness are important factors, which determine the degree of machinability and the performance of both the cutting tool and the work piece material. In this study, numerical models obtained from the Response Surface Methodology (RSM) and Artificial Neural Network (ANN) techniques were used for predicting the magnitude of the temperature and surface roughness during the machining operation of titanium alloy (Ti6Al4V). The design of the numerical experiment was carried out using the Response Surface Methodology (RSM) for the combination of the process parameters while the Artificial Neural Network (ANN) with 3 input layers, 10 sigmoid hidden neurons and 3 linear output neurons were employed for the prediction of the values of temperature. The ANN was iteratively trained using the Levenberg-Marquardt backpropagation algorithm. The physical experiments were carried out using a DMU80monoBLOCK Deckel Maho 5-axis CNC milling machine with a maximum spindle speed of $18000 \mathrm{rpm}$. A carbide-cutting insert (RCKT1204MO-PM $\mathrm{S} 40 \mathrm{~T}$ ) was used for the machining operation. A professional infrared video thermometer with an LCD display and camera function (MT 696) with infrared temperature range of $-50-1000^{\circ} \mathrm{C}$, was employed for the temperature measurement while the surface roughness of the work pieces were measured using the Mitutoyo SJ - 201, surface roughness machine. The results obtained indicate that there is high degree of agreement between the values of temperature and surface roughness measured from the physical experiments and the predicted values obtained using the ANN and RSM. This signifies that the developed RSM and ANN models are highly suitable for predictive purposes. This work can find application in the production and manufacturing industries especially for the control, optimization and process monitoring of process parameters.
\end{abstract}

KEYWORDS: ANN, algorithm, RSM, surface roughness, temperature.

\section{INTRODUCTION}

Titanium alloy (Ti-6Al-4V) is characterized by excellent mechanical properties, such as high tensile strength, high stiffness, good formability and excellent corrosion resistance in addition to its outstanding strength-to-weight ratio. It finds an extensive range of applications in different industries, such as biomedical, aerospace, automotive, marine, railway etc. 1, 2]. Its ease of formability via extrusion often makes it a preferred choice for the development of complex and intricate profiles and its outstanding strength-toweight ratio often promotes energy and environmental sustainability. However, its low value of thermal conductivity and Young modulus often results in a poor surface finish and dimensional inaccuracies during the machining operations 3 . Since, the degree of the surface finish often influences the product's quality, integrity and performance, the optimization of the process parameter is key during the machining operation of the titanium alloy. Titanium alloys are classified into three groups namely, alpha $(\alpha)$, alpha-beta $(\alpha-\beta)$ and beta $(\beta)$. Commercially pure titanium and its alloys are mainly used in cryogenic applications while the $\alpha-\beta$ alloys (mostly Ti-6Al-4V) are extensively used in the aerospace industries for the development of aircraft components, such as airframes and engine components [4 6 . The $\beta$ alloys find application in high strength applications due to its good forgeability [7 9]. Temperature is an important parameter, which determines changes in the mechanical behaviour, microstructure, surface finish and performance of the work piece as well as the cutting tool during machining operations. Cutting operations under controlled temperature can enhance the cutting oper- 
ation with the development of products with relieved residual stresses, good surface finish and mechanical properties. On the contrary, cutting operations under uncontrolled temperature can decrease the useful life of the cutting tool and decrease the overall process sutainability and promote a poor surface finish of the final product. It can also bring about significant reduction in the yield and ultimate tensile strength of the work piece material, thereby subsequently resulting in an increase in the strain fracture, crack growth and fatigue behaviour of both the cutting tool and the work piece [10, 11]. The cutting temperature increases as the major energy required for the cutting operation is converted into heat at the primary shear zone where the main cutting action takes place and at the secondary deformation zone of the chip-tool interface due to friction, as well as in the work piecetool interface [12, 13]. The heat distribution across the work piece, tool and chips formed based on their configurations and their thermal conductivities results in temperature changes. The understanding of the temperature variation during a cutting operation will assist in the design and selection of the right cutting tool, as well as machinability analysis of the cutting process. It will also assist in the selection of the appropriate cutting fluid and the determination of the energy requirements of the process. The energy requirements of the process influence the sustainability of the process in terms of its cost effectiveness and environmental friendliness. Since temperature is a critical factor during machining operation, the amount of heat conducted by the tool and the work piece should be controlled to prevent a tool wear, surface roughness of the work piece material, dimensional inaccuracy, oxidation and corrosion. Some of the control actions to keep cutting temperature within the permissible limit involves the use of coolants, real time monitoring of cutting temperature via the use of infrared video thermometers and the process optimization of cutting parameters, such as the depth of cut, cutting force, speed of cutting, feed rate etc. The control actions are necessary because research has proven that a lack of an effective temperature monitoring and control can significantly contribute to temperature variations during the machining operation [14-16]. An increase in the temperature distribution during the cutting action often increases the power consumption of the cutting process with the risk of increasing the dimensional inaccuracy and surface roughness of the work piece. It could also trigger a plastic deformation of the cutting edge of the tool, which can result in a tool wear and fracture. Several methods, such as the analytical and numerical methods icluding the Taguchi, Response Surface Methodology, Artificial Neural Network (ANN) etc. have been proposed for the prediction of the temperature and other process parameters during the cutting operations [17-21]. This is because aforementioned approaches have proven to be suitable for the modelling and prediction of impor- tant process parameters and also capable of reducing the numbers of expensive physical experimentation runs. The only challenge is that the wrong selection of models may cause variations in the analysis of the temperature distribution when analytical or numerical results are compared with the results from the physical experimentations. Over the years, the ANN has been used extensively as a modelling technique to study the relationship between the input and output variables in order to make predictions. The tool finds applications in the modelling and optimization of simple as well as complex linear and non-linear systems with multi-dimensional relationships [22 25]. Another important parameter considered in this study beside the temperature is the surface roughness of the finished work piece. The surface roughness index is used to indicate the level of surface irregularities or finish during the machining operations. It is a parameter, which determines the quality of the final product and its ability to meet the design specifications and its functional requirements [26]. The correlation between temperature and surface roughness is that when the cutting temperature exceeds the optimum, the surface roughness of the work piece will increase. In addition, when the cutting temperature falls below the threshold under cutting conditions, there is a likelihood for the surface roughness of the work piece to increase. Hence, the need to keep the temperature values within the optimum range. Both the RSM and the ANN tools have been deployed for the Design of Experiment (DoE) as well as an intelligent computation and prediction of the process parameters during machining operations in order to keep process paramters within the optimum range and enhance the overall efficiency or sustainability of the cutting process. For instance, Kanta and Sangwan [27, performed a predictive modelling and optimization of the machining parameters in order to minimize the surface roughness of titanium alloy using ANN and Genetic Algorithm (GA). Kovak et al. 28 applied the fuzzy logic and regression analysis for modelling of the surface roughness in a face milling operation while Campatelli et al. 29] employed the Response Surface Methodology (RSM) for the optimization of the power consumption during machining operations. In addition, Djavanroodi et al. 30] used the ANN for the modelling of an equal channel angular pressing process while Fathallah et al. 31] carried out the mathematical modelling and optimization of surface quality and productivity during the turning process of AISI 12L14 free-cutting steel. From these works, the modelling and optimization techniques present applicable solutions for the correlation and determination of the optimum process conditions during the machining operations. Furthermore, the developed models and techniques indicate a good agreement between the predicted values and output target values, which indicate that the techniques are capable of determining the optimum range of the process parameters. The aim 
of this work is to demonstrate the application of the Response Surface Methodology (RSM) and Artificial Neural Network (ANN) for the correlation and prediction of the temperature and surface roughness duuring the millling operation of titanium alloy (Ti6Al4V). In view of this, a comparative analysis between the results obtained from both approaches (RSM and ANN) were carried out in order to determine their suitability for a predictive purpose.

\section{MATERIALS AND METHODS}

The chemical composition as well as the mechanical and thermal properties of the titanium alloy (Ti-6Al$4 \mathrm{~V}$ ) employed in this study are presented in Tables 1 and 2 respectively.

Equation 1 expresses the average surface roughness, which gives an indication of the height variation of the surface of the material.

$$
R_{a}=\frac{1}{l} \int_{0}^{l}|Z(x)| d x
$$

where: $Z$ is the profile ordinates of the roughness profile.

The temperature $\theta_{i}$ at the chip- tool interface is expressed as Equation 2

$$
\theta_{i}=k_{1} E_{c} \sqrt{\frac{v_{c} a_{1}}{\lambda c_{v}}}
$$

where: $k_{1}$ is a constant based on the cutting tool and work piece material, $E_{c}$ is the specific cutting energy (Joule), $V_{c}$ is the average cutting velocity $(\mathrm{mm} / \mathrm{sec})$, $a_{1}$ is the thickness of the uncut chip ( $\left.\mathrm{mm}\right), \lambda$ is the thermal conductivity $(\mathrm{W} / \mathrm{m} \cdot \mathrm{K})$, and $c_{v}$ is the volume specific heat $\left(\mathrm{J} / \mathrm{K} / \mathrm{m}^{3}\right)$.

Since the tool life is a function of the cutting temperature, the Taylor's equation for the estimation of the tool life is expressed as Equation 3

$$
V T^{n}=C
$$

where: $V$ is the cutting speed $(\mathrm{mm} / \mathrm{min}), T$ is the tool life expectancy (mins) $n$ and $C$ are the exponent and constant depending on the cutting tool, work piece material and process parameters.

The tool life can also be determined from Equation 4

$$
V T^{n} f^{a} d^{b}=C
$$

where: $f$ and $d$ are the feed and depth of cut respectively $(\mathrm{mm})$, while $a$ and $b$ are the exponents, which depends on the cutting tool, work piece material and process parameters.

The physical experiments were carried out using a DMU80monoBLOCK Deckel Maho 5-axis CNC milling machine with a maximum spindle speed of $18000 \mathrm{rpm}$. A carbide-cutting insert (RCKT1204MOPM S40T) was used for the machining operation. A solid rectangular work piece of Ti6Al4V was screwed to the stationary dynamometer (KISTLER 9257A
8-Channel Summation of Type 5001A Multichannel Amplifier) and mounted directly to the machine table. The milling operations were performed at different cutting parameters of feed rate, spindle speed, cutting speed, and depth of cut. The cutting force data were collected with the aid of the Data Acquisition System (DAS) connected to a computer. A professional infrared video thermometer with an LCD display and camera function (MT 696) with an infrared temperature range of $-50-1000^{\circ} \mathrm{C}$, response time of less than $300 \mathrm{~ms}$, resolution of 0.1 to over $1000^{\circ}$ Cand IR basic accuracy of \pm 1.0 reading was employed for the temperature measurement in real time.

The experimental set up and the connections of the KISTLER dynamometer to the 5-axis CNC milling machine are shown in Figure 1.

The Sandvik carbide insert (RCKT1204MO-PM S40T) employed for the cutting and the work piece (Ti6Al4V) are shown in Fig. 2.

The specifications of the cutting tool are presented in Table 3

The surface roughness of the samples of the work piece were measured using the Mitutoyo SJ - 201, surface roughness machine (Fig. 3).

\subsection{The Response SURFACE Methodology}

The feasible combination of the process parameters was done using the Response Surface Methodology (RSM). The choice of the RSM was based on its ability to iteratively study the cross-effect of process parameters [33 35]. The numerical experimentation comprises a four factor experimental design, which varied at different levels in the following ranges; feed rate $(250-350 \mathrm{~mm} / \mathrm{rev})$, spindle speed $(1000-3000 \mathrm{rpm})$, cutting speed $(100-300 \mathrm{~m} / \mathrm{min})$ and depth of cut $(0.3-0.9 \mathrm{~mm})$. The feasible combinations of these process parameters produced 41 experimental trials whose response (surface roughness and temperature) were determined via the physical experimentations. The statistical analysis of both the numerical and physical experimentations were used to obtain two mathematical models for correlating and predicting the magnitude of the surface roughness and temperature respectively, as a function of the independent process parameters.

\subsection{THE ANN APPROACH}

The Artificial Neural Network (ANN) with sigmoid hidden neurons and linear output neurons fits the prediction problem given the consistent data and enough neurons in its hidden layer (Figure 4). The network was trained with the Levenberg-Marquardt backpropagation algorithm in a MATLAB 2018 B environment. The choice of the algorithm was based on the fact that it is highly efficient for correlative and training purposes and typically requires more memory, but less time 36. The training automatically stops when generalization stops improving, as indicated by an increase in the mean square error of the validation 


\begin{tabular}{lccccc}
\hline Element & $\mathrm{Al}$ & $\mathrm{Fe}$ & $\mathrm{O}$ & $\mathrm{Ti}$ & $\mathrm{V}$ \\
\hline Percent weight (wt.\%) & 6 & 0.25 & 0.2 & 90 & 4 \\
\hline
\end{tabular}

TABLE 1. Chemical composition of titanium alloy (Ti-6Al-4V) [32.

\begin{tabular}{llc}
\hline S/N & Properties & Value \\
\hline \multicolumn{2}{l}{ Mechanical } \\
\hline 1. & Density & $45000 \mathrm{~kg} / \mathrm{m}^{3}$ \\
2. & Brinell's hardness & 334 \\
3. & Yield strength & $880 \mathrm{MPa}$ \\
4. & Ultimate tensile strength & $950 \mathrm{MPa}$ \\
5. & Bulk modulus & $150 \mathrm{GPa}$ \\
6. & Modulus of elasticity & $113.8 \mathrm{GPa}$ \\
7. & Poison's ratio & 0.342 \\
8. & Shear modulus & $44 \mathrm{GPa}$ \\
9. & Shear strength & $550 \mathrm{MPa}$ \\
\hline Thermal & \\
\hline 1. & Specific heat capacity & $0.5263 \mathrm{~J} / \mathrm{g}^{\circ} \mathrm{C}$ \\
2. & Thermal conductivity & $6.7 \mathrm{~W} / \mathrm{m} \cdot \mathrm{K}$ \\
3. & Melting point & $1660^{\circ} \mathrm{C}$ \\
4. & Coefficient of Thermal expansion & $8.70 \mathrm{~K}{ }^{-1}$ \\
\hline
\end{tabular}

TABLE 2. Mechanical and thermal properties of titanium alloy (Ti-6Al-4V) [32].

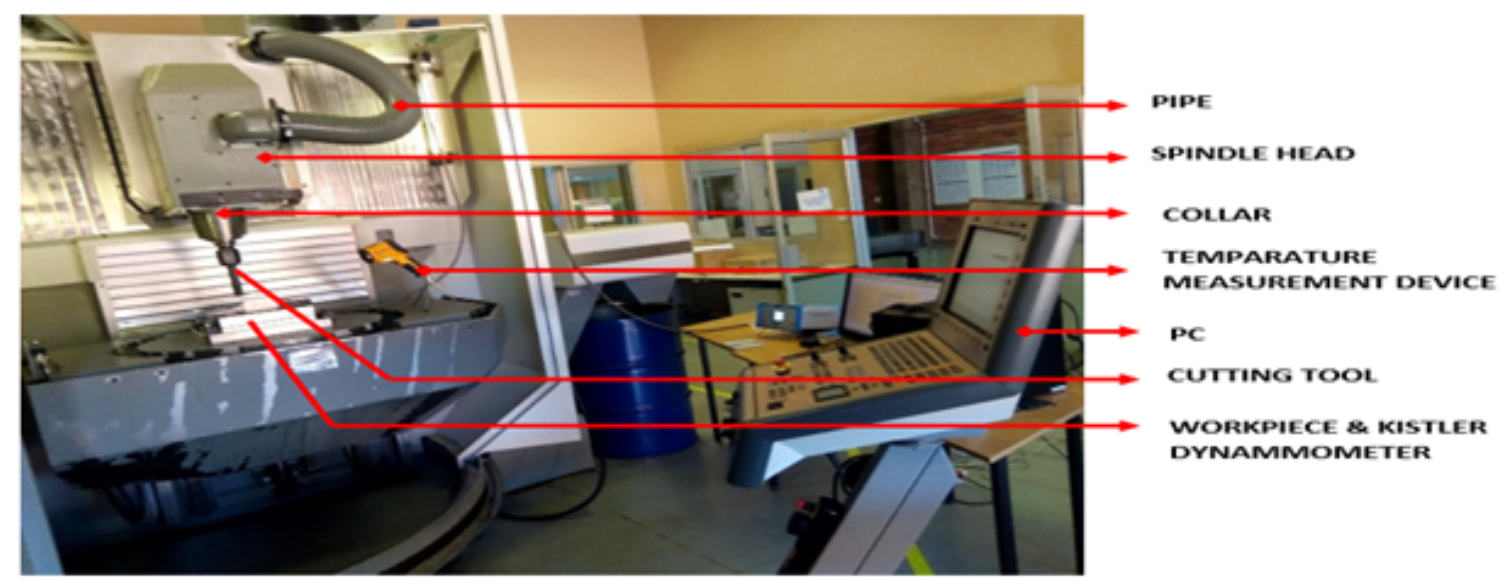

FiguRE 1. Experimental set up.

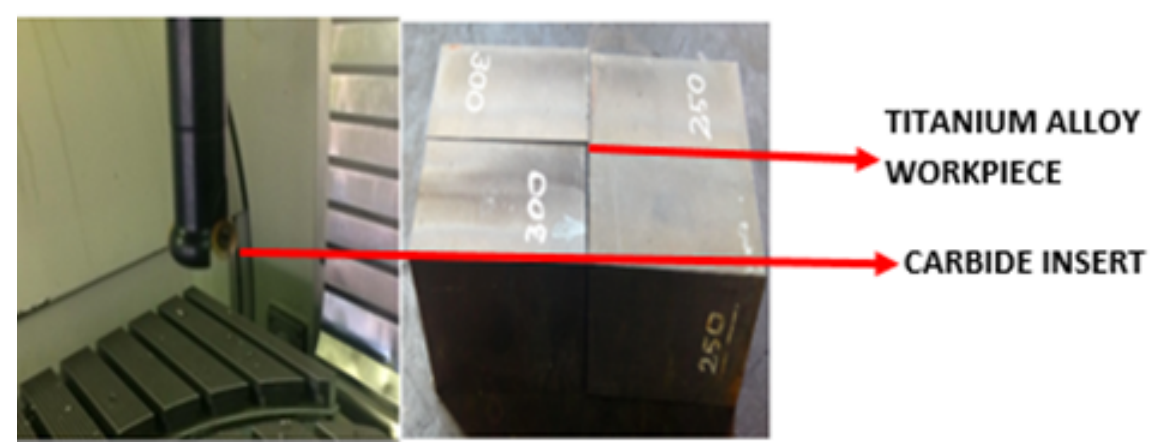

FiguRE 2. The carbide cutting tool and the work piece (Ti6Al4V). 


\begin{tabular}{cll}
\hline Symbol & Parameter & Value \\
\hline$T_{d}$ & Inscribed circle diameter $(\mathrm{mm})$ & 3.987 \\
$d_{c}$ & Depth of cut $(\mathrm{mm})$ & 1.760 \\
$\alpha$ & Nose Radius (mm) & 6.000 \\
$t$ & Insert thickness (mm) & 4.750 \\
$\varphi$ & Lead angle (deg.) & $0^{\circ}$ \\
\hline
\end{tabular}

TABLE 3. The cutting tool geometry.

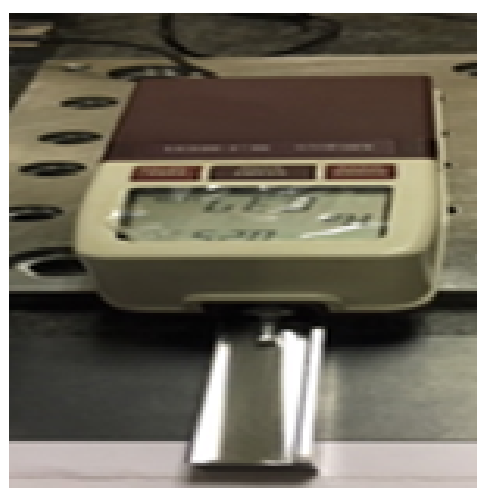

Figure 3. Mitutoyo SJ - 201, surface roughness machine.

samples. The architecture of the neural network comprises three input and output layers comprising 10 neurons in the hidden layer and 3 neurons in the output layer. The total number of inputs is the same as the number of experimental trials carried out (41) and the same as the number of the outputs. ANN performs better with a large data set, however, the data set employed in this study is limited to 41 because of cost considerations since it is a preliminary analysis. For a detailed analysis, it is necessary to increase the number of samples and data sets in order to enhance the performance of the ANN.

The trainlm network training function, which updates the weights and biases according to LevenbergMarquardt optimization, was employed. This is because it is often the fastest backpropagation algorithm in the Neural Network toolbox, and is highly suitable for supervised learning, although it requires more memory than other algorithms 36.

From the physical experimentations, the feed rate, spindle speed and the cutting velocity were used as the input parameters while the depth of cut, surface roughness and temperature serve as the output target. The grouping of the input and the output target are as follow;

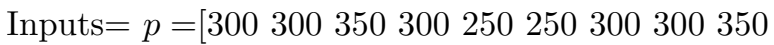
250250300325350300300350275350325350325 325325325325350300350325300350300325300 325300300325300375 ; 250100300100200200300 300300200250300200250300200300100300200 100200100200200200200200300300300100200 100100100100200100200 300; 0.60 .30 .30 .60 .6 $\begin{array}{llllllllllllll}0.9 & 0.6 & 0.9 & 0.6 & 0.3 & 0.3 & 0.6 & 0.3 & 0.3 & 0.3 & 0.9 & 0.6 & 0.9 & 0.6\end{array}$

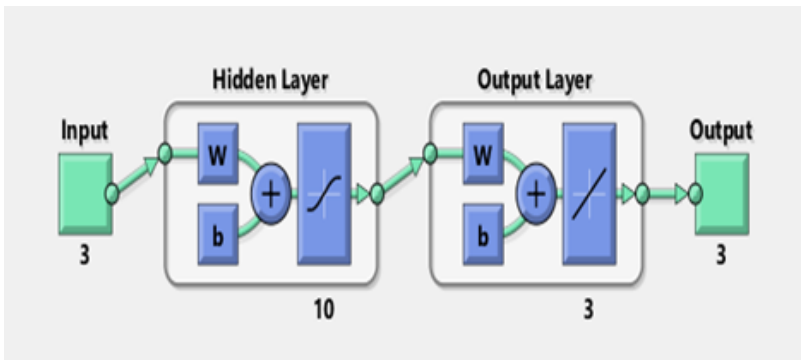

FiguRE 4. The architecture of the neural network.

$\begin{array}{llllllllllllll}0.6 & 0.6 & 0.6 & 0.6 & 0.9 & 0.3 & 0.3 & 0.6 & 0.6 & 0.9 & 0.9 & 0.3 & 0.3 & 0.3\end{array}$ $\left.\begin{array}{llllllll}0.9 & 0.6 & 0.9 & 0.3 & 0.6 & 0.9 & 0.6 & 0.3\end{array}\right]$;

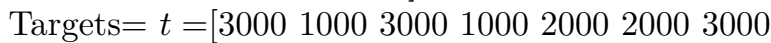
1000300020001000200020001000300010002000 1000200030002000200020002000200010003000 3000300020002000300030003000100010002000 $100010002000 \quad 3000 ; 0.790 .910 .86 \quad 0.98 \quad 0.750 .78$ $\begin{array}{lllllllllllllll}0.83 & 0.88 & 0.84 & 0.70 & 0.79 & 0.88 & 0.84 & 0.52 & 0.60 & 0.96 & 0.97\end{array}$ $\begin{array}{llllllllllllll}0.98 & 0.99 & 0.58 & 0.56 & 0.74 & 0.77 & 0.86 & 0.85 & 0.79 & 0.88 & 0.46\end{array}$ $\begin{array}{lllllllllllll}0.66 & 0.80 & 0.87 & 0.76 & 0.95 & 0.79 & 0.98 & 0.78 & 0.80 & 0.87 & 0.58\end{array}$ $0.770 .54 ; 1761608516512414017015614515795$ 93878860100120180165158177186168175145 1231271808778989692102105125136140155 $160156]$;

The number of the neurons in the hidden layer $\left(h_{n}\right)$ is the weighted sum of inputs and bias, expressed as Equation 5

$$
h_{n}=\sum(w i)+b
$$

Where $w$ is the weight of the input parameters, $i$ is the number of input parameters and $b$ is the bias.

For the three input data parameters employed for this study (the feed rate, spindle speed and the cutting velocity), the number of the neurons in the hidden layer was obtained as ten and the corresponding number of the output layer and expected output parameters was three (depth of cut, surface roughness and temperature) as shown in Figure 4 .

The trained neural network then produced two mathematical models for correlating the network outputs while predicting the magnitudes of the surface roughness and temperature.

\section{Results AND Discussion}

\subsection{Results FROM THE RESPONSE SURFACE METHODOLOGY}

The statistical analysis of the developed model for predicting surface roughness as a fucntion of the independent process parameters (feed rate, spindle speed, cutting velocity and depth of cut) as well as its Analysis of Variance (ANOVA) are presented in Tables 4 and 5 respectively.

the "p-value Prob $>$ F" was less than 0.050 for the overall model term $(0.0299<0.05)$. This indicates that the overall model term is statistically significant. The statistical significance of the overall model term implies that certain model term is a critical 


\begin{tabular}{lcccccc}
\hline Statistical parameters & Sum of squares & df & Mean square & F value & $\begin{array}{c}\text { p-value } \\
\text { Prob }>\text { F }\end{array}$ & Remarks \\
\hline Model & 0.23 & 5 & 0.046 & 3.02 & 0.0299 & Significant \\
B-Spindle speed & 0.034 & 1 & 0.034 & 2.21 & 0.502 & 0.5796 \\
C-Cutting velocity & $4.817 \mathrm{E}-3$ & 1 & $4.817 \mathrm{E}-3$ & 0.32 & 0.1989 \\
D-Depth of Cut & 0.027 & 1 & 0.027 & 1.75 & 0.0751 & Not significant \\
BC & 0.053 & 1 & 0.053 & 3.46 & 7.35 & 0.0122 \\
BD & 0.11 & 1 & 0.11 & & \\
Residual & 0.37 & 24 & 0.015 & & & \\
Lack of Fit & 0.26 & 19 & 0.014 & 0.63 & & \\
Pure Error & 0.11 & 5 & 0.022 & & & \\
Corr Total & 0.60 & 29 & & & & \\
\hline
\end{tabular}

TABle 4. The statistical analysis of the developed model (Surface roughness).

\begin{tabular}{lcc}
\hline Parameter & Value & Remarks \\
\hline R-Squared & 0.9675 & Significant \\
Adj R Squared & 0.9879 & Significant \\
Predicted R-Squared & 0.9609 & Significant \\
Adeq. Precision & 6.8300 & Significant \\
\hline
\end{tabular}

TABle 5. The Analysis of Variance (ANOVA) for the developed model (Suface roughness).

factor (specifically model term BD) that could influence the magnitude of the measured response (surface roughness). In this instance, the factors (statistical parameters) are: B (spindle speed), C (cutting velocity), D (depth of cut), BC (cross effect of the spindle speed and cutting velocity) and BD (cross effect of the spindle speed and the depth of cut). The significant model term was BD $(0.0122<0.05)$. The "Lack of Fit" value of 0.63 implies that the lack of fit is not statistically significant relative to the pure error. There is a $78.91 \%$ chance that a "Lack of Fit-F-value" this large could occur due to noise. The non-significance of the "Lack of Fit" value implies that the model is good for a predictive purpose. The values of the Adjusted R-square (0.9879) and Predicted R square (0.9609) were in a reasonable agreement with the $\mathrm{R}$ squared (0.9675), and were all close to 1 , thus, indicating that the model is suitable for correlative predictive purposes. In addition, the Adeq. Precision, which is a measure of the signal to noise ratio has a value greater than 4, which is desirable. This implies that the model is suitable for navigating the design space.

The results obtained from both the numerical and physical experimentations were statistically analysed using the RSM to obtain a predictive model, which correlates the surface roughness as a function of the significant independent process parameters, namely the feed rate and depth of cut (Equation 6).

$$
\begin{aligned}
& \text { Surface Roughness }=+0.77-0.038 B- \\
& \quad-0.014 C+0.033 D-0.058 B C+0.084 B D
\end{aligned}
$$

Where; $B$ is the spindle speed $(\mathrm{mm}), C$ is the cutting velocity $(\mathrm{m} / \mathrm{min})$ and $D$ is the depth of cut $(\mathrm{mm})$.
Equation 6 is a first order 2FI model equation and it was found to be adequate for the predictive and correlative purposes relating to the surface roughness of the samples. The non-significance of the "Lack of Fit" value implies that the model equation is good for a predictive purpose. If the "Lack of Fit" is significant, other model equations, such as the quadratic or a cubic model equations, can be considered.

Figure 5 is the normal plot of the residuals for the developed model for surface roughness. This plot shows the degree, to which the data set is normally distributed. The closeness of the data to the average (diagonal) line indicates that the residuals are approximately linear (normally distributed), although with an inherent randomness left over within the error portion. The departure of data points from the average line were marginal and found to be between the permissible range of $\pm 10 \%$ in a relation to the average line. The approximately linear pattern obtained is an indication of a normally distributed data set and the development of an accurate model, which can be used for predictive and correlative purposes. In addition, the data set does not assume a non-linear pattern and there was no outliner (a data point that significantly falls outside the average line) in the plot, thus, indicating that the residual terms are normally distributed.

The statistical analysis of the developed model for predicting the cutting temperature as a function of the independent process parameters (feed rate, spindle speed, cutting velocity and depth of cut) as well as its Analysis of Variance (ANOVA) are presented in Tables 6 and 7 respectively.

The model "F-value" of 2.11 implies that the model is statistically significant. There is only a $9.88 \%$ chance that the model "F-value" this large could occur due to noise. In addition, the value of the "p-value Prob $>$ F" of the overall model term was 0.0001 . The fact that the value of the "p-value Prob > F" was less than 0.050 indicates that the model terms are statistically significant. The statistical significance of the overall model term means that certain model term is a critical factor (specifically model term $\mathrm{AD}$ ) 
Design-Expert( $\circledast^{3}$ Software Surface roughness

Color points by value of Surface roughness: 0.99

0.46

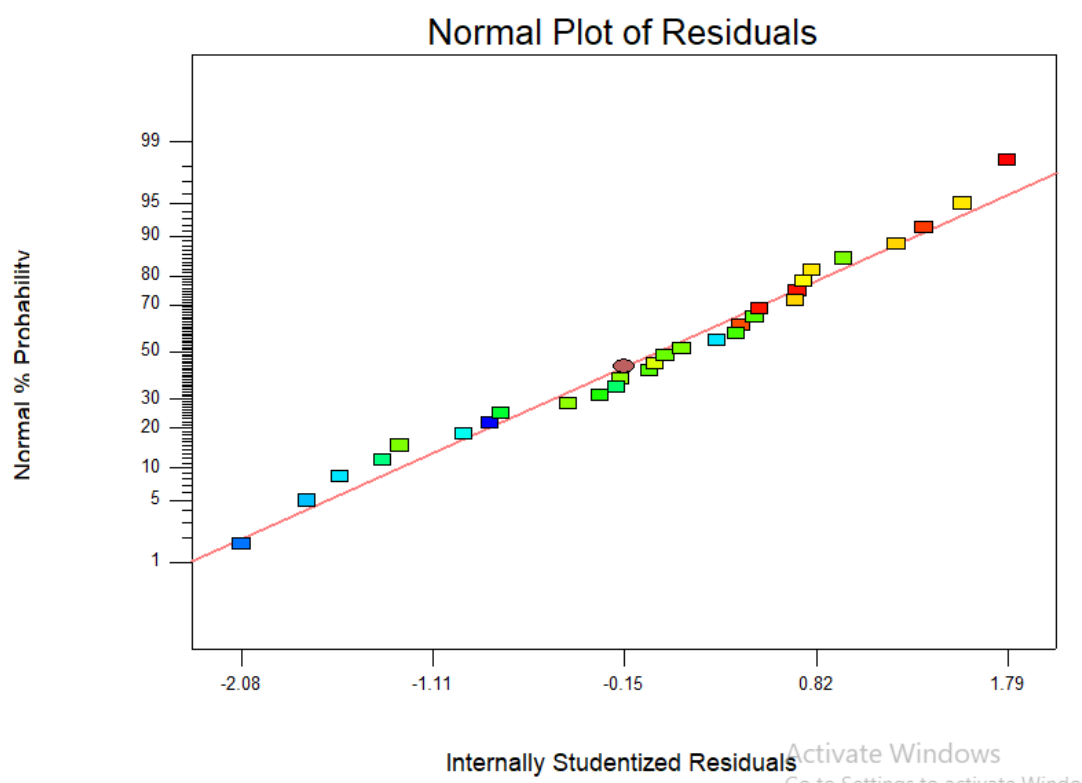

FiguRE 5. The normal plot of residuals (surface roughness).

\begin{tabular}{lcccccc}
\hline Statistical parameters & Sum of squares & df & Mean square & F value & $\begin{array}{c}\text { p-value } \\
\text { Prob }>\text { F }\end{array}$ & Remarks \\
\hline Model & 11882.92 & 5 & 2376.58 & 2.11 & 0.0001 & Significant \\
A-Feed rate & 198.38 & 1 & 198.38 & 0.18 & 0.6783 & \\
B-Spindle speed & 18.38 & 1 & 18.38 & 0.016 & 0.8994 & \\
D-Depth of Cut & 10001.04 & 1 & 10001.04 & 0.89 & 0.3550 & Not significant \\
AB & 3052.56 & 1 & 3052.56 & 2.71 & 0.1126 & \\
AD & 7612.56 & 1 & 7612.56 & 6.77 & 0.0157 & \\
Residual & 27004.95 & 24 & 1125.21 & & & \\
Lack of Fit & 18574.95 & 19 & 977.64 & 0.58 & & \\
Pure Error & 8430.00 & 5 & 1686.00 & & & \\
Corr Total & 38887.87 & 29 & & & & \\
\hline
\end{tabular}

TABLE 6. The statistical analysis of the developed model (Temperature).

that could influence the magnitude of the measured response (Temperature). In this instance, the factors (statistical parameters) are: factors A (feed rate), B (spindle speed), D (depth of cut), AB (cross effect of the feed rate and spindle speed) and $\mathrm{AD}$ (cross effect of the feed ate and the depth of cut). The significant model term was AD $(0.0157<0.05)$. Values greater than 0.05 indicate that the model term is not statistically significant at $95 \%$ confidence level. The "Lack of Fit" value of 0.58 implies that the lack of fit is not statistically significant relative to the pure error. There is a $82.26 \%$ chance that a "Lack of Fit-F-value" this large could occur due to noise. The non-significance of the "Lack of Fit" value implies that the model is good for a predictive purpose. The values of the Adjusted R-square (0.9008) and Predicted R square $(0.9100)$ are in a reasonable agreement with the $\mathrm{R}$ squared (0.9105), and were all close to 1 , thus, indicating that the model is suitable for correlative predictive purposes. In addition, the Adeq. Precision is a measure of the signal to noise ratio and a value

\begin{tabular}{lcc}
\hline Parameter & Value & Remarks \\
\hline R-Squared & 0.9008 & Significant \\
Adj R Squared & 0.9100 & Significant \\
Predicted R-Squared & 0.9105 & Significant \\
Adeq. Precision & 5.494 & Significant \\
\hline
\end{tabular}

TABle 7. The Analysis of Variance (ANOVA) the developed model.

greater than 4 is usually desirable hence a value of 5.494 obtained for the Adeq. Precision implies that the model is suitable for navigating the design space.

The results obtained from both the numerical and physical experimentations were statistically analysed using the RSM to obtain a predictive model, which correlates the temperature as a function of the significant independent process parameters, namely the feed rate and depth of cut (Equation 7).

Temperature $=+128.73+2.87 A-0.88 B-$ 


Design-Expert( Software
Temperature
Color points by value of
Temperature:
$\begin{aligned} & 186 \\ & 60\end{aligned}$

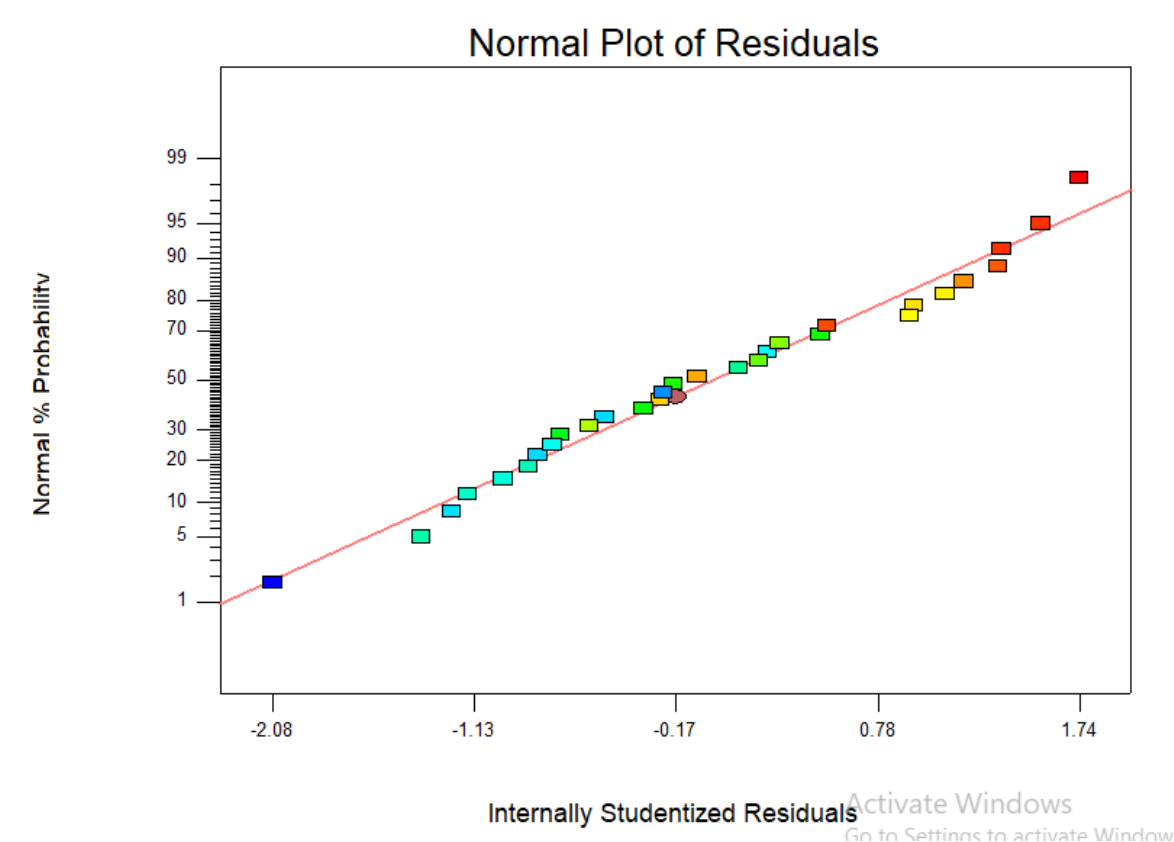

FiguRE 6. The normal plot of residuals (Temperature).

$$
-6.46 D-13.81 A B+21.81 A D
$$

where: $A$ is the feed rate $(\mathrm{mm}) B$ is the spindle speed (rpm) and $D$ is the depth of cut $(\mathrm{mm})$.

Equation 7 is a first order 2 FI model equation and was found to be adequate for the predictive and correlative purposes relating to the machining temperature. The non-significance of the "Lack of Fit" value implies that the model equation is good for a predictive purpose. If the "Lack of Fit" is significant, other model equations, such as the quadratic or a cubic model equations, can be considered.

Figure 6 shows the normal plot of the residuals for the developed model of temperature prediction. Similar to Figure 5 the closeness of the data to the average (diagonal) line indicates that the residuals are approximately linear (normally distributed) although with an inherent randomness left over within the error portion. The departure of data points from the average line were marginal and found to be between the permissible range of $\pm 10 \%$ in relation to the average line. The approximately linear pattern obtained is an indication of a normally distributed data set and the development of an accurate model, which can be used for predictive and correlative purposes. In addition, the data set does not assume a non-linear pattern and there was no outliner (a data point that significantly falls outside the average line) in the plot, thus, indicating that the residual terms are normally distributed.

The depth of cut, which measures the distance penetrated by the cutter in the work piece is a function of the rate of material removal while the cutting speed is a measure of the relative velocity between the cutting tool and the work piece during the cutting operation. The spindle speed is the rotational frequency of the machine's spindle, which measures the number of revolutions of the spindle per minute while the feed rate measures the velocity at which the cutter is fed past the work piece per revolution [37.

Figures 7 and 8 are the contour and 3D plots, which show the effect of the spindle speed and cutting velocity on the surface roughness of the material. An increase in the magnitude of the cutting velocity was observed to result in an increase in the magnitude of the surface roughness. This can be due to the fact that an increase in the relative velocity between the cutting tool and work piece can result in an increase in the temperature distribution in the tool and work piece material due to increase in frictional activities, thus, causing an increase in the magnitude of the surface roughness. This challenge can be mitigated via the application of an effective cooling strategy to reduce the frictional activities and heat generation at the cutting interfaces. With the application of the cutting fluid, machining under high speed can be beneficial in the sense that it will promote time and cost effectiveness of the machining operation and also increase the rate of material removal while bringing the product to the required surface finish condition.

Figures 9 and 10 are the contour and the 3D interactive plots, which show the effect of the spindle speed and depth of cut on the surface roughness of the work piece respectively. The relationship between the spindle speed and the depth of cut was found to be inversely proportional from the plots. An increase in the depth of cut was observed to produce an increase in the magnitude of the surface roughness and vice versa. On the contrary, the magnitude of the surface roughness was observed to decrease with an increase in the spindle speed and vice versa. This may be due to the fact that a decrease in the depth 
Design-Expert( Software

Surface roughness

- Design Points

0.99

0.46

$\mathrm{X} 1=\mathrm{B}:$ Spindle speed $\mathrm{X} 2$ = C: Cutting velocity

Actual Factors

A: Feed rate $=300.00$

D: Depth of cut $=0.60$

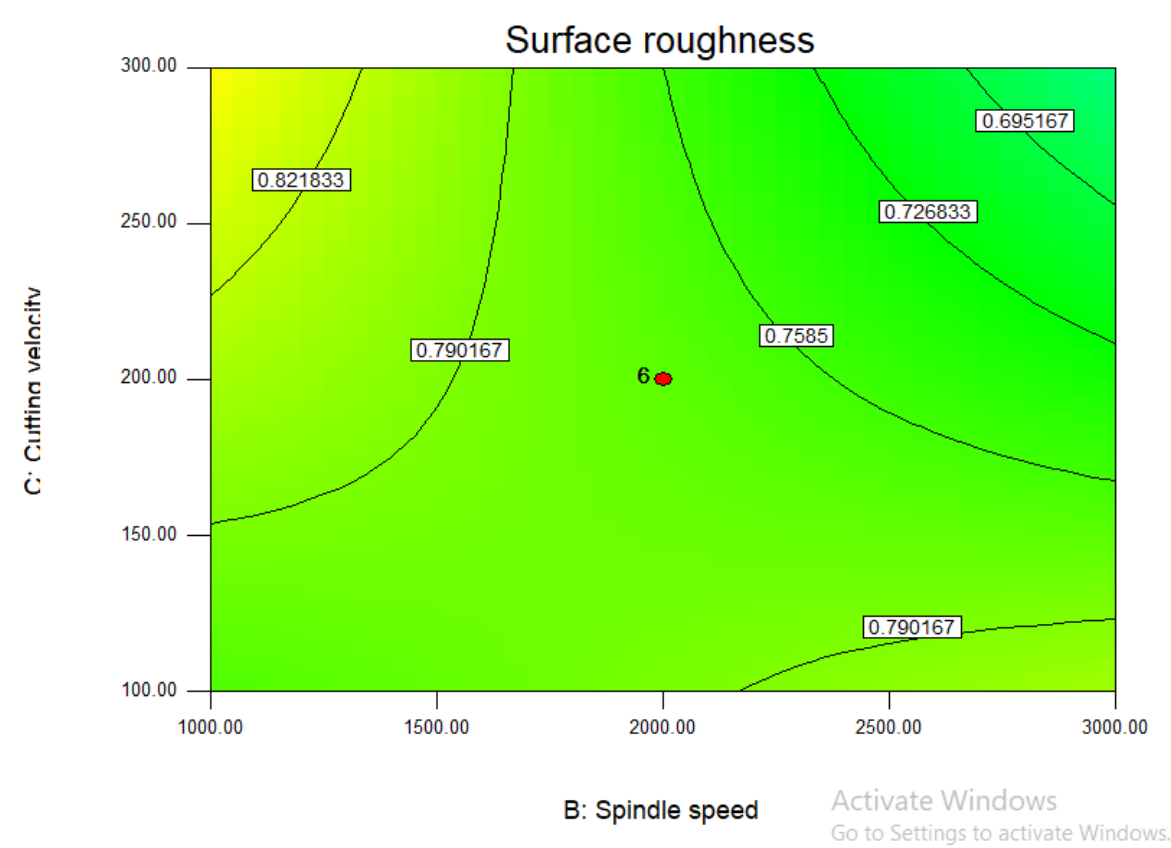

FIGURE 7 . The contour plot of the spindle speed and cutting velocity.

\section{Surface roughness}

0.99

0.46

X1 = B: Spindle speed $\mathrm{X} 2$ = C: Cutting velocity

Actual Factors

A: Feed rate $=300.00$

D: Depth of cut $=0.60$

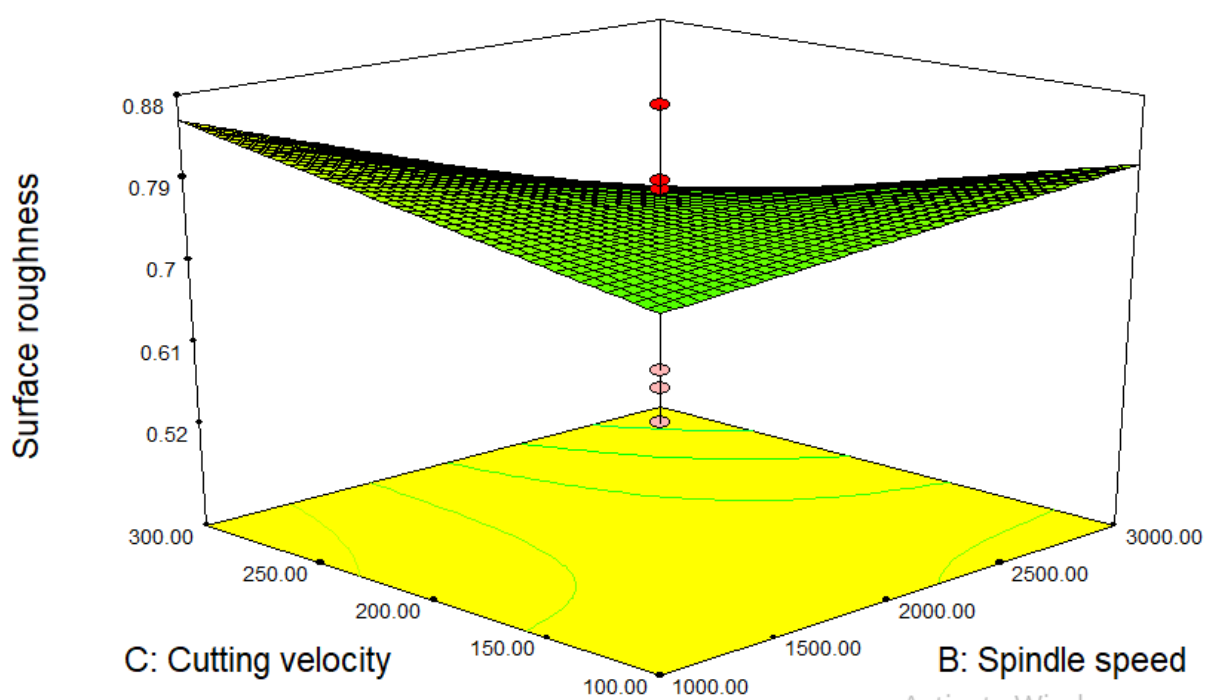

Activate Windows

Go to Settings to activate Window

Figure 8 . The interactive 3D plot of the spindle speed and cutting velocity. 
Design-Expert $\circledast$ Software

Surface roughness

- Design Points

0.99

0.46

X1 = B: Spindle speed X2 = D: Depth of cut

Actual Factors

A: Feed rate $=300.00$

C: Cutting velocity $=200.00$

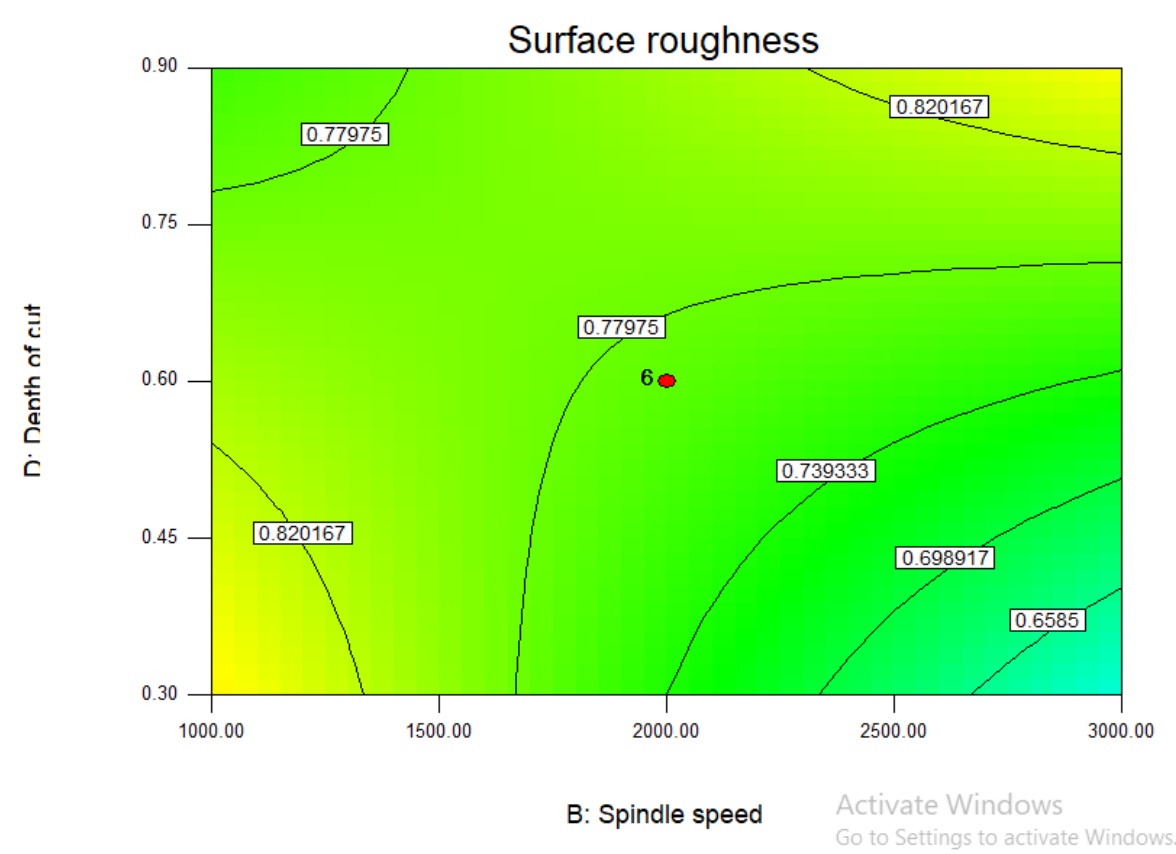

Figure 9. The contour plot of the spindle speed and depth of cut.

Design-Expert( Software

\section{Surface roughness \\ 0.99 \\ 0.46}

$\mathrm{X} 1=\mathrm{B}:$ Spindle speed X2 = D: Depth of cut

Actual Factors

A: Feed rate $=300.00$

C: Cutting velocity $=200.00$

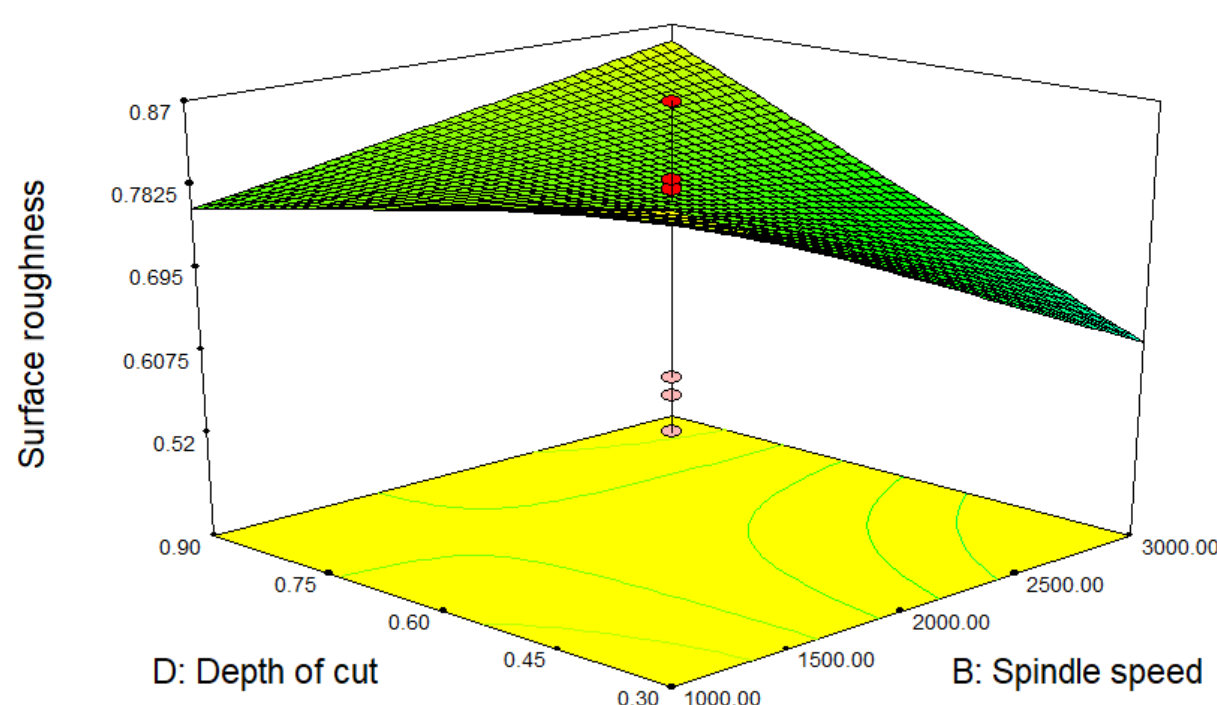

Activate Windows

Figure 10. The interactive 3D plot of the spindle speed and depth of cut. 
of cut may result in an increase in the surface area to volume ratio of the work piece, thereby promoting frictional activities at the tool-work piece interface and subsequently, increase in the surface roughness of the material [26]. Furthermore, each revolution of the machine's spindle represents a smaller circumferential distance, therefore, an increase in the spindle speed may cause the circumferential distance to decrease. As the tool approaches the work piece for material removal, the spindle speed may cause the work piece surface to decrease, thereby decreasing the frictional activities and the possibility for the development of a built up edge at the tool-work piece interface. Hence, this phenomenon promotes a significant reduction in the magnitude of surface roughness. This agrees significantly with the findings of Kumar et al. [38.

Figures 11 and 12 are the contour and the 3D interactive plots, which show the effect of the feed rate and spindle speed on the cutting temperature during the machining operation. The relationship between the feed rate and the spindle was found to be directly proportional. An increase in the magnitude of the feed rate was observed to result in an increase in the magnitude of the temperature and vice versa. In addition, an increase in the magnitude of the spindle speed was also observed to result in an increase in the magnitude of the cutting temperature and vice versa. As the velocity, at which the cutting tool is fed past the work piece (feed rate), increases, the energy requirement of the cutting process may increase with an increase in the magnitude of the cutting temperature. This is in an accordance with the law of energy conservation as part of the energy input is converted to heat energy, which subsequently promotes an increase in the cutting temperature. Furthermore, as the magnitude of the spindle speed increases, the energy requirement of the process also increases with a tendency for a temperature build-up, if an effective cooling strategy is not put in place.

Figures 13 and 14 are the contour and the 3D interactive plots, which show the effect of the feed rate and depth of cut on the cutting temperature during the machining operation. The relationship between the depth of cut and the feed rate, in this case, was found to be directly proportional. An increase in the magnitude of the depth of cut and feed rate was found to result in a significant reduction in the magnitude of the cutting temperature and vice versa. This may be attributed to the fact that an increase in the depth of cut may result in a decrease in the surface area of the work piece, which promotes the quick heat dissipating capacity of the applied coolants at the tool-work piece interface due to the reduced surface. The effectiveness of the coolants within a small area of the work piece may account for a significant reduction in the magnitude of the cutting temperature at the shear zone. The findings indicate that the process parameters and machining conditions are key parameters, which influence the rate of machinability, degree of surface finish as well as process economics and sustainability, hence the need for an effective process design and control 39, 40.

\subsection{Results from the Artificial Neural NETwORK (ANN)}

Figure 15 presents the performance-training plot, which consists of the training and the iteration lines. The plot indicates the iteration at which the performance goal (target) was met. The ease of convergence of both the training and the iteration lines at the 98th iteration indicates that the developed network is adequate for the predictive purpose as indicated by the training line, which cuts through the vertical line and the negligible value of the Mean Square Error $\left(10^{-4}\right)$. The figure shows the plots of the three major steps for the modelling process using neural network, the training, validation and testing plots. The validation plot is used to estimate the adequacy of the network for the predictive purpose while tuning the weights and biases during the neural network development. The training plot measures the performance and accuracy of the developed network during the prediction. The epoch indicates the number of iterations carried out before the network was suitable for correlative and predictive purposes. The similarity in the pattern of the validation and the test plots indicate that there is no overfitting of the data set, which may affect the suitability of the network for predictive purpose. The best validation performance was obtained after the 92nd iteration, after which six more iterations were carried out before the training automatically stopped. Hence, the minimum number of iterations that produced the best validation performance was 92 .

Table 8 presents the results obtained from the feasible combinations of process parameters using the Response Surface Methodology (RSM) as well as the values of the surface roughness and the actual temperature obtained via the physical experiments. This serves as the input and output parameters of the developed neural network.

Figure 16 is a plot of the gradient, training gain $\mathrm{Mu}$ and validation check after the network has been adequately trained. The gradient was $4.2011 \cdot 10^{-4}$ while the training gain $\mathrm{Mu}$ was $1.00 \cdot 10^{-7}$ at the 98 th iteration. The training stopped at the 98th iteration due to the increase in error as the data sets begin to overfit. Thus, the best validation performance that indicates neither significant error nor validation check failure was observed at the 92nd iteration. Beyond the 98th iteration, the validation checks carried out begin to fail as indicated by the Figure. The small values of the gradient $\left(4.2011 \cdot 10^{-4}\right)$ and the training gain $\left(1.00 \cdot 10^{-7}\right)$ indicate that the difference between the output and the target is negligible. The error first reduces up to the 98th epochs of training, but may start to increase due to overfitting the training data by the network after the 98 th iteration. 
Design-Expert( $\circledast^{-}$Software

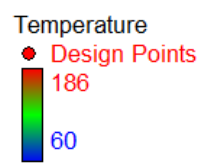

$\mathrm{X} 1=\mathrm{A}:$ Feed rate $\mathrm{X} 2$ = B: Spindle speed

Actual Factors

C: Cutting velocity $=200.00$

D: Depth of cut $=0.60$

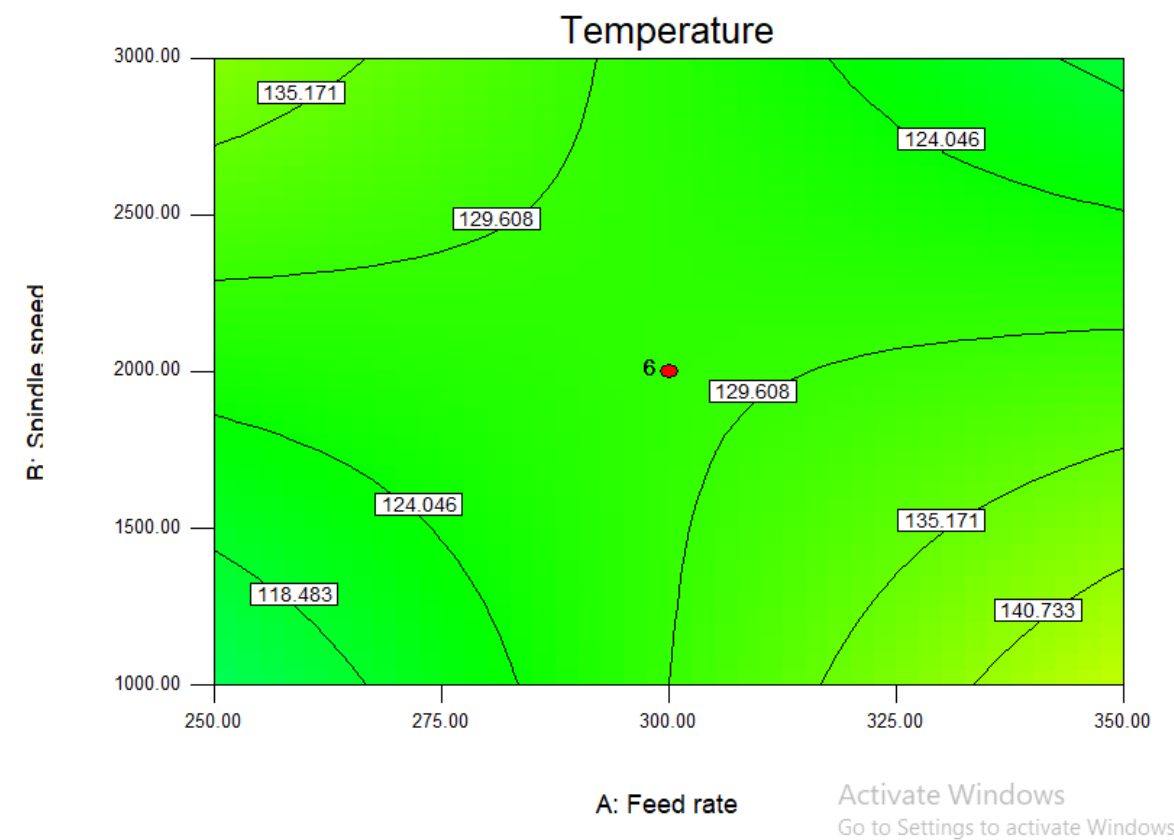

Figure 11. The contour plot of the feed rate and spindle speed.

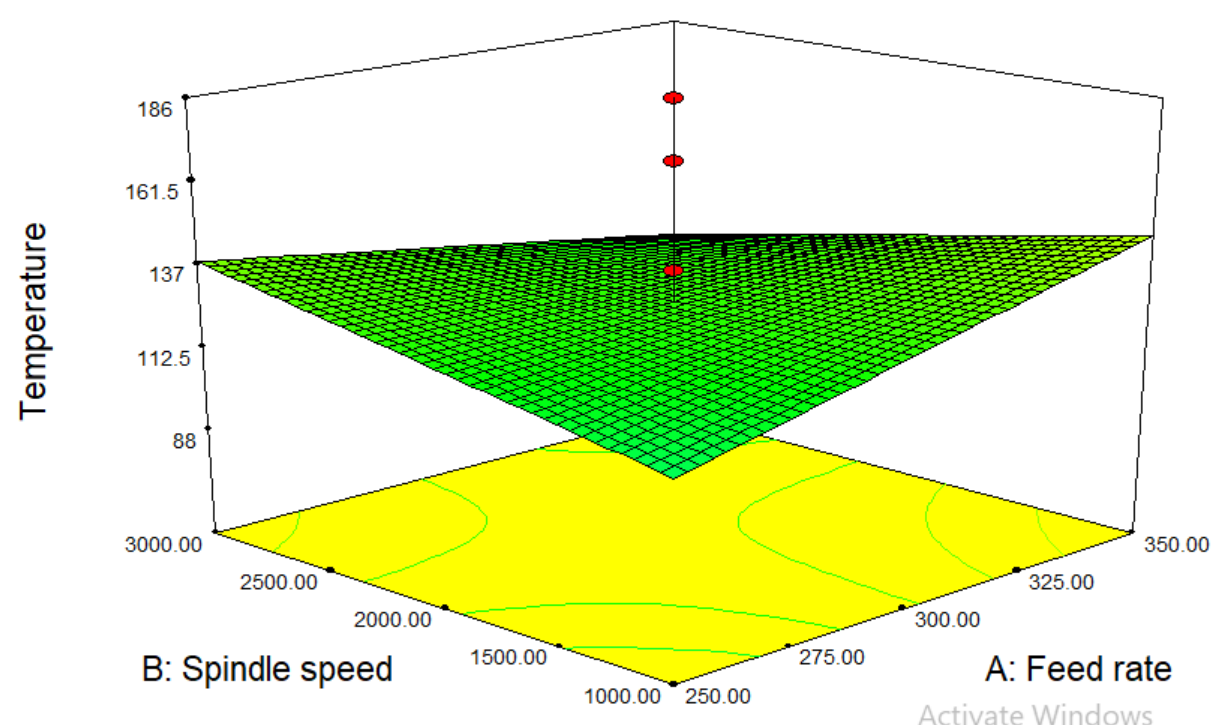

Figure 12. The interactive 3D plot of the feed rate and spindle speed. 
Design-Experts Software

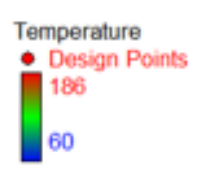

$\mathrm{X} 1=\mathrm{A}:$ Feed rate

X2 $=$ D: Depth of cut

Actual Factors

B: Spindle speed $=2000.00$

C. Cutting velocity $=200.00$

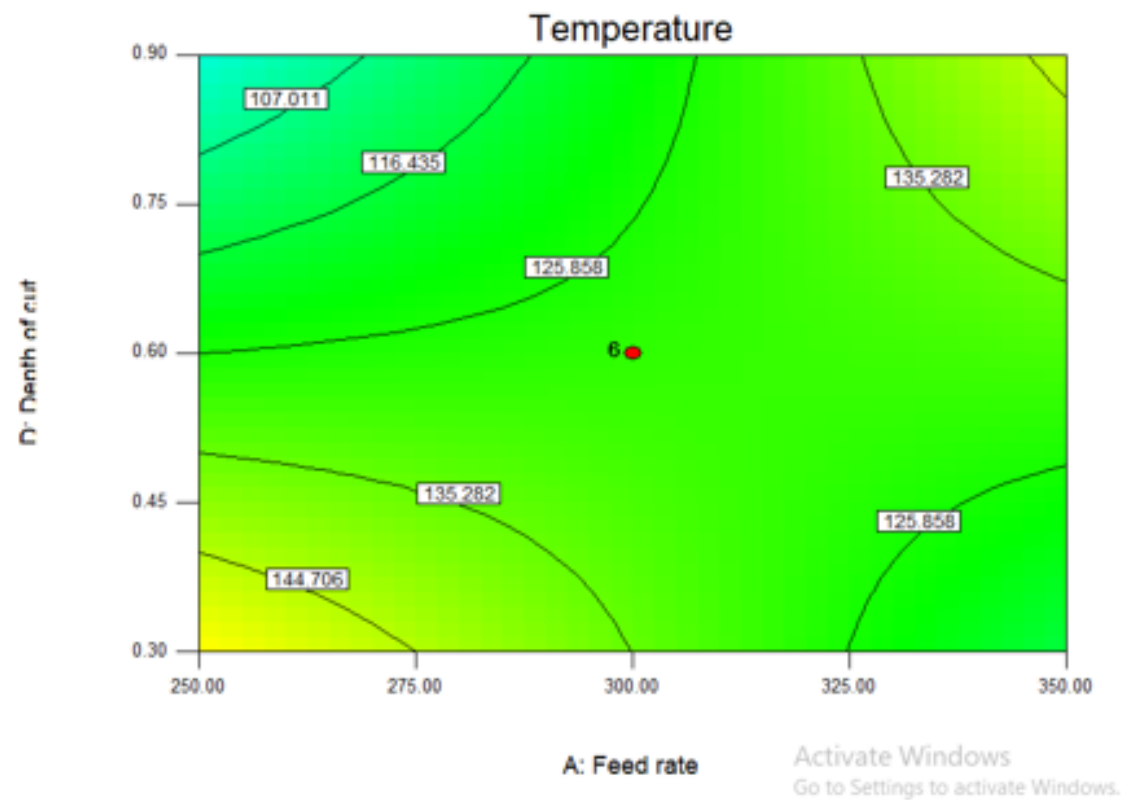

FiguRE 13. The contour plot of the feed rate and depth of cut.
Design-Expert® Software

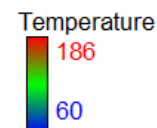

$\mathrm{X} 1=\mathrm{A}:$ Feed rate

$\mathrm{X} 2$ = D: Depth of cut

\section{Actual Factors}

B: Spindle speed $=2000.00$

C. Cutting velocity $=200.00$

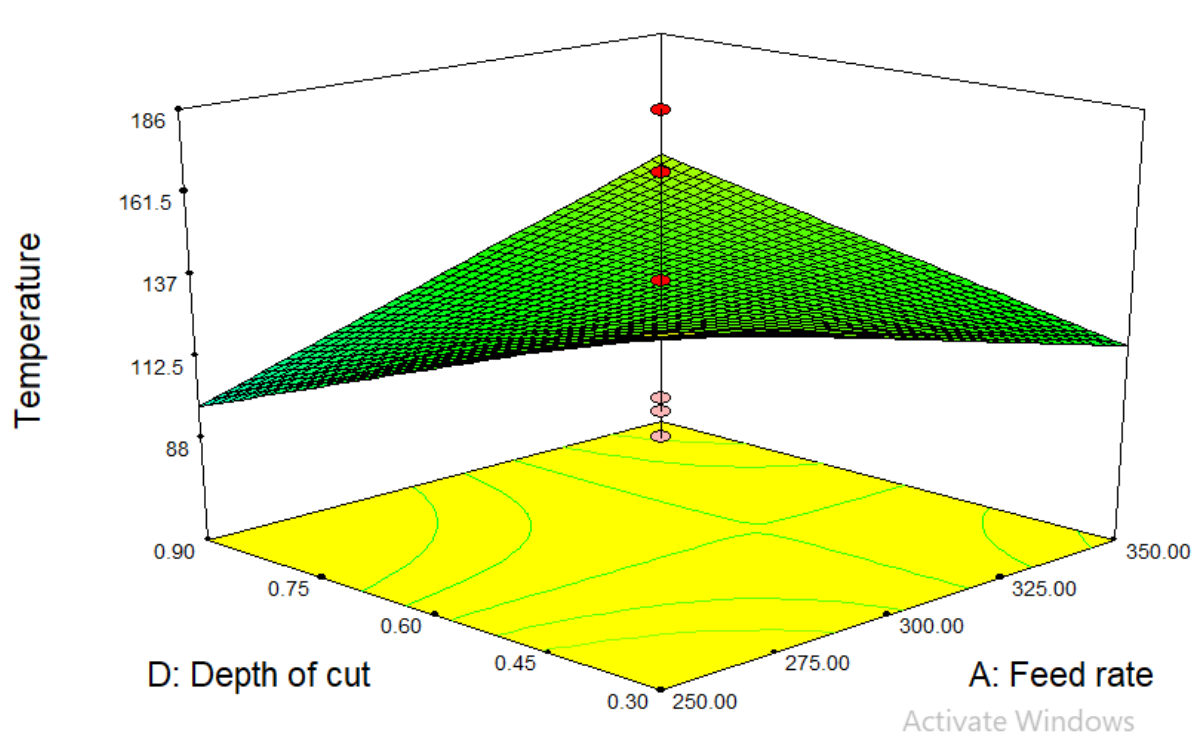

Figure 14. The interactive 3D plot of the feed rate and depth of cut. 


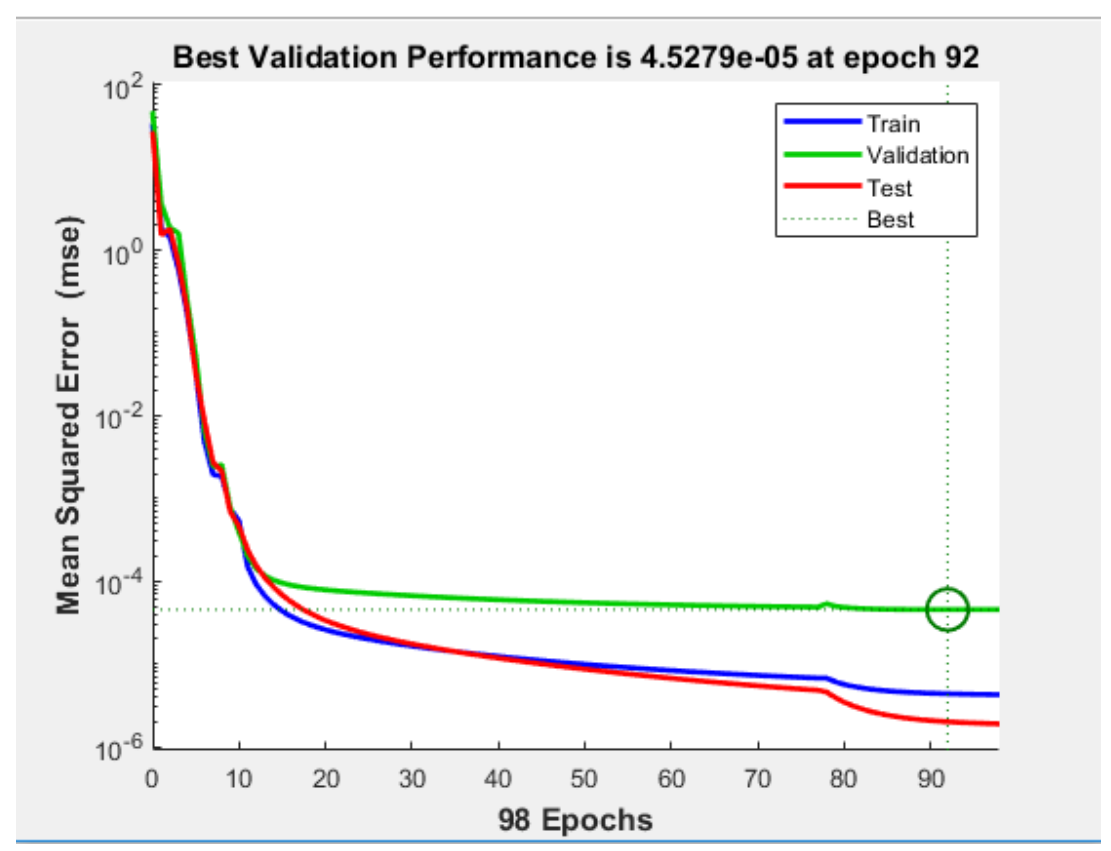

FiguRE 15. Performance training graph.
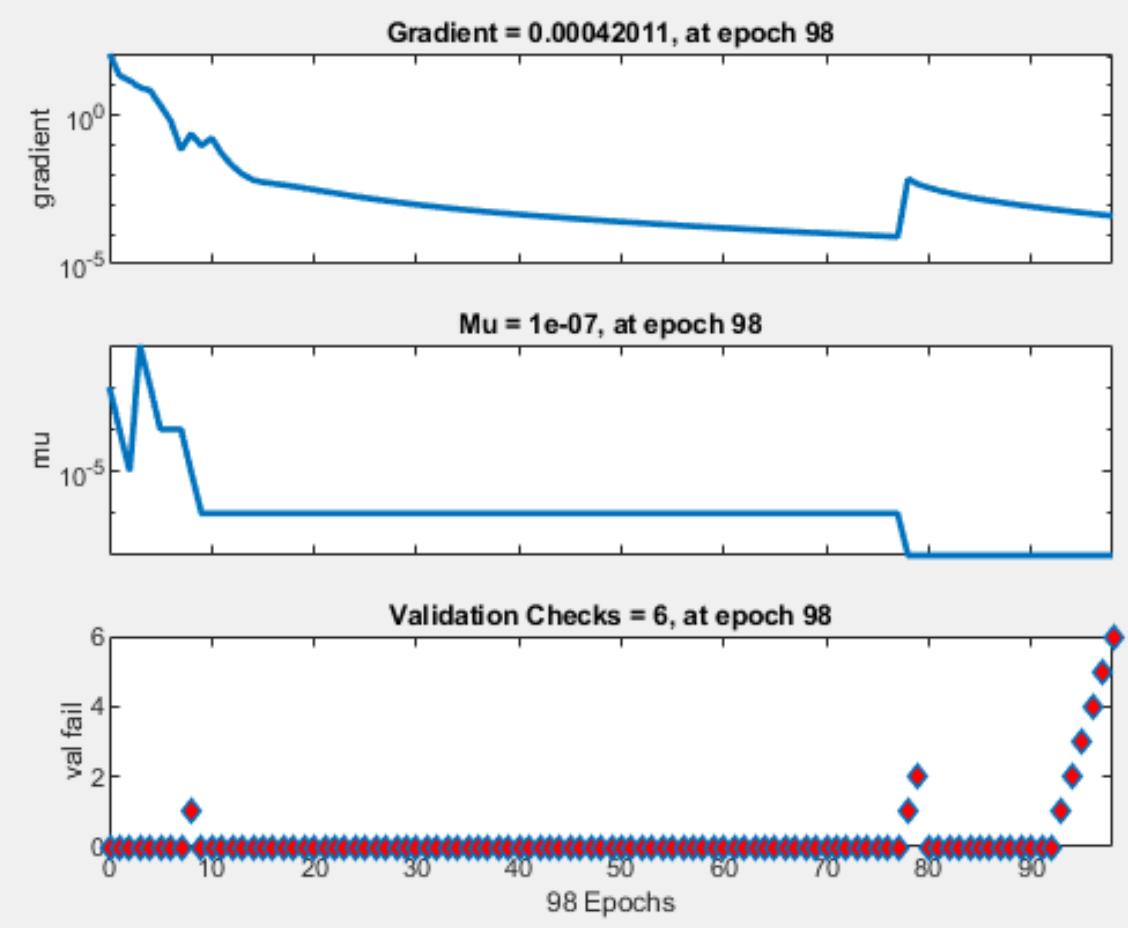

FiguRE 16. The plot of the gradient, training gain $\mathrm{Mu}$ and validation check. 


\begin{tabular}{|c|c|c|c|c|c|c|}
\hline $\begin{array}{l}\text { Experimental } \\
\text { trials }\end{array}$ & $\begin{array}{l}\text { Feed rate } \\
(\mathrm{mm} / \mathrm{rev})\end{array}$ & $\begin{array}{l}\text { Spindle } \\
\text { speed } \\
(\mathrm{rpm})\end{array}$ & $\begin{array}{l}\text { Cutting } \\
\text { velocity } \\
(\mathrm{m} / \mathrm{min})\end{array}$ & $\begin{array}{l}\text { Depth } \\
\text { of cut } \\
(\mathrm{mm})\end{array}$ & $\begin{array}{c}\text { Average } \\
\text { Surface Roughness } \\
(\mu \mathrm{m})\end{array}$ & $\begin{array}{l}\text { Actual } \\
\text { Temp. } \\
\left({ }^{\circ} \mathrm{C}\right)\end{array}$ \\
\hline 1. & 300 & 3000 & 250 & 0.60 & 0.79 & 176 \\
\hline 2. & 300 & 1000 & 100 & 0.30 & 0.91 & 160 \\
\hline 3. & 350 & 3000 & 300 & 0.30 & 0.86 & 85 \\
\hline 4. & 300 & 1000 & 100 & 0.60 & 0.98 & 165 \\
\hline 5. & 250 & 2000 & 200 & 0.60 & 0.75 & 124 \\
\hline 6. & 250 & 2000 & 200 & 0.90 & 0.78 & 140 \\
\hline 7. & 300 & 3000 & 300 & 0.60 & 0.83 & 170 \\
\hline 8. & 300 & 1000 & 300 & 0.90 & 0.88 & 156 \\
\hline 9. & 350 & 3000 & 300 & 0.60 & 0.84 & 145 \\
\hline 10. & 250 & 2000 & 200 & 0.30 & 0.70 & 157 \\
\hline 11. & 250 & 1000 & 250 & 0.30 & 0.79 & 95 \\
\hline 12. & 300 & 2000 & 300 & 0.60 & 0.88 & 93 \\
\hline 13. & 325 & 2000 & 200 & 0.30 & 0.84 & 87 \\
\hline 14. & 350 & 1000 & 300 & 0.30 & 0.52 & 88 \\
\hline 15. & 300 & 3000 & 100 & 0.30 & 0.60 & 60 \\
\hline 16. & 350 & 1000 & 300 & 0.90 & 0.96 & 100 \\
\hline 17. & 275 & 2000 & 200 & 0.60 & 0.67 & 120 \\
\hline 18. & 350 & 1000 & 100 & 0.90 & 0.98 & 180 \\
\hline 19. & 325 & 2000 & 200 & 0.60 & 0.99 & 165 \\
\hline 20. & 350 & 3000 & 100 & 0.60 & 0.58 & 158 \\
\hline 21. & 325 & 2000 & 200 & 0.60 & 0.56 & 177 \\
\hline 22. & 325 & 2000 & 200 & 0.60 & 0.74 & 186 \\
\hline 23. & 325 & 2000 & 200 & 0.60 & 0.77 & 168 \\
\hline 24. & 325 & 2000 & 200 & 0.90 & 0.86 & 175 \\
\hline 25. & 325 & 1000 & 200 & 0.30 & 0.85 & 145 \\
\hline 26. & 350 & 3000 & 300 & 0.30 & 0.79 & 123 \\
\hline 27. & 300 & 3000 & 300 & 0.60 & 0.88 & 127 \\
\hline 28. & 350 & 3000 & 300 & 0.60 & 0.46 & 180 \\
\hline 29. & 325 & 2000 & 100 & 0.90 & 0.66 & 87 \\
\hline 30. & 300 & 3000 & 200 & 0.90 & 0.80 & 78 \\
\hline 31. & 350 & 3000 & 100 & 0.30 & 0.87 & 98 \\
\hline 32. & 300 & 3000 & 100 & 0.30 & 0.76 & 96 \\
\hline 33. & 350 & 1000 & 100 & 0.30 & 0.95 & 92 \\
\hline 34. & 325 & 1000 & 100 & 0.90 & 0.79 & 102 \\
\hline 35. & 300 & 2000 & 200 & 0.60 & 0.98 & 105 \\
\hline 36. & 325 & 1000 & 100 & 0.90 & 0.78 & 125 \\
\hline 37. & 300 & 2000 & 200 & 0.30 & 0.80 & 136 \\
\hline 38. & 300 & 1000 & 300 & 0.60 & 0.87 & 140 \\
\hline 39. & 325 & 1000 & 300 & 0.90 & 0.58 & 155 \\
\hline 40. & 300 & 2000 & 200 & 0.30 & 0.77 & 160 \\
\hline 41. & 375 & 3000 & 300 & 0.60 & 0.54 & 156 \\
\hline
\end{tabular}

TABLE 8. The results obtained from both the physical and numerical experiments. 
Figure 17 shows the statistical validation of the developed network. The errors obtained by finding the difference between the targets and outputs from the network were represented by a histogram. As shown by the Figure, the values of the error were insignificant. The bins are the number of vertical bars on the plot and each bar represents the number of samples from the data set. In this case, the total number of the bins was 20. The value of the error, which is the difference between the target and the output of the network, ranges from a minimum value of $-4.73 \cdot 10^{-3}$ to a maximum value of $2.224 \cdot 10^{-2}$. This was divided into 20 smaller bins and the error was calculated as follow;

$$
\begin{gathered}
\text { Error }=\frac{2.224 \cdot 10^{-2}-\left(-4.73 \cdot 10^{-3}\right)}{20} \\
\text { Error }=1.3485 \cdot 10^{-3}
\end{gathered}
$$

The width of the error corresponds to $1.3485 \cdot 10^{-3}$.

Furthermore, the error at the left hand side of the plot was $-4.70 \cdot 10^{-4}$ when the vertical height of the bin for the data validation was 35 . This implies that 35 samples from the validation data set have errors that fall in the range. The error range is, therefore, calculated as follow;

$$
\begin{aligned}
\text { Error range }=( & \frac{-4.70 \cdot 10^{-4}-1.3485 \cdot 10^{-3}}{2} ; \\
& \left.\frac{-4.70 \cdot 10^{-4}+1.3485 \cdot 10^{-3}}{2}\right)
\end{aligned}
$$

$$
\text { Error range }=\left(-9.1075 \cdot 10^{-4} ; 4.3925 \cdot 10^{-4}\right)
$$

The range of error corresponds to $-4.70 \cdot 10^{-4}$ at the left hand side of the graph. Similarly, the errors for other bins can be analysed likewise. The range of error is very small and negligible, thus, indicating a high degree of agreement between the targets and the network outputs. This also signifies a high probability that the predictions from the network will be accurate.

As shown in Figure 18, the developed network was validated by creating a regression plots to show the relationship between the outputs of the network and the targets. In other words, the regression plots show the degree of agreement between the values obtained from the physical and numerical experimentations. The Mean Squared Error (MSE) is the average squared difference between outputs and targets. Lower values signify small and negligible error, hence, the lower the value of the MSE, the better the developed network and vice versa. Zero means no error. The regression coefficient $\mathrm{R}$ is the measure of the correlation between outputs and targets. An R-value of 1 means a close relationship while zero indicates a random relationship. The correlation coefficient $\mathrm{R}$ of the first regression plot for the training was 0.95119 , which indicates that there is a near exact linear relationship between outputs and targets, hence, the agreement between the values of the physical and numerical experimentations can be declared highly significant. The second regression plot is the validation plot, which is used to examine the suitability of the developed model for predictive purposes. The correlation coefficient $\mathrm{R}$ obtained was 0.81089 . This is close to 1 , which also indicates that the network is capable of performing the predictive function accurately with minimal deviations from the target. The reduction in the value of the correlation coefficient stems from the fact that the size of the data sample was relatively small. The larger the size of the data sets, the more efficient the predictive ability of the network and vice versa. The closer the value of the correlation coefficient $\mathrm{R}$ to 1 , the better the network, which indicates a minimal difference between the target and the network output. The value of the correlation coefficient $\mathrm{R}$ can be made closer to 1 , by increasing the size of the data set while adjusting the weights and biases of the network architecture. The third regression plot is the test plot, which is a direct function of the performance of the network during prediction. This has a correlation coefficient of 0.95119 . The fourth regression plot represents the overall performance of the network architecture. The correlation coefficient obtained for this was 0.92373 . This is relatively close to 1 , which indicates the suitability of the developed model for predicting the temperature and surface roughness during the milling operation of titanium alloy (Ti6Al4V).

The model equations for the prediction of the magnitude of the surface roughness as well as temperature from the ANN models are expressed as Equations 8 and 9 respectively.

$$
\begin{gathered}
\text { Output } Y, \text { Linear Fit : } Y=(0.38) T+(0.49) \\
\text { Output } Y, \text { Linear Fit : } Y=(0.26) T+(99)
\end{gathered}
$$

where: $T$ is the target variable.

Table 9 compares the actual value of the temperature and surface roughness from the physical experimentations with the predicted values obtained with the aid of the ANN. The high degree of agreement between the values of temperature and surface roughness from the physical experimentations and the predicted temperature using ANN indicates that the developed network is highly suitable for the predictive purpose.

Figures 19 and 20 show the actual and predicted values of the temperature and surface roughness for the milling operation of Ti6Al4V respectively, using the RSM and ANN. The similarity in the data sets and pattern of the plots indicate the closeness of the predicted values to the actual values. This also indicates the accuracy and the effectiveness of the RSM and ANN for correlative and predictive purposes. However, the ANN demonstrated a better predictive ability than the RSM as observed by the magnitude of its predictions being closer to the actual values for both the temperature and the surface roughness as opposed to the RSM, though, the errors generated by both approaches were negligible and were found to be within the permissible limit (Table 9). 


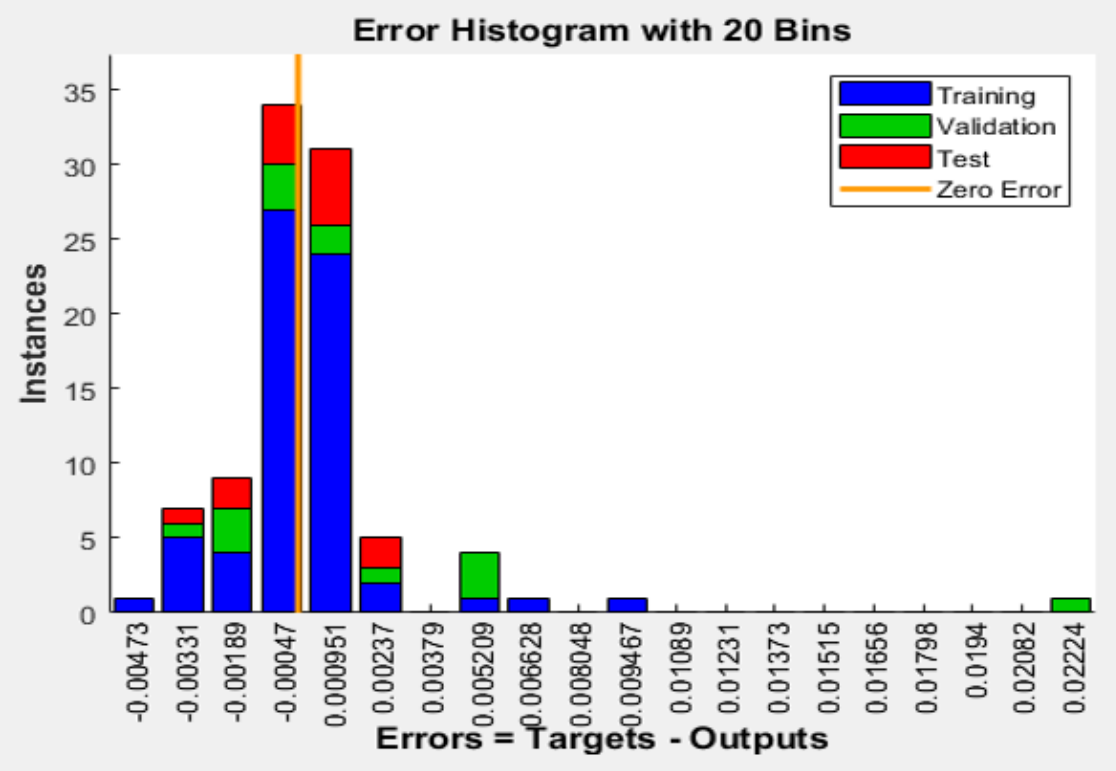

Figure 17. The error histogram plot.
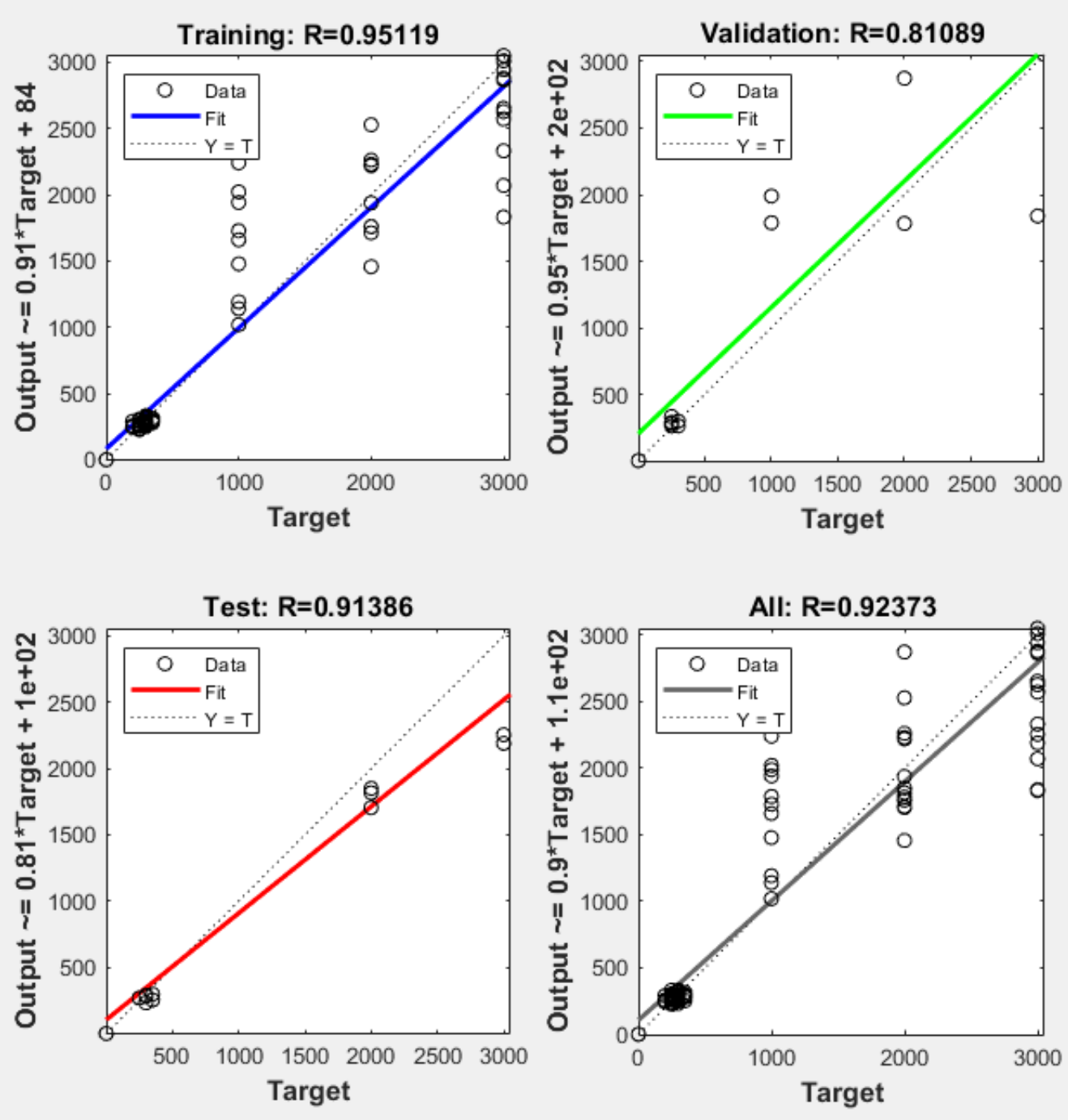

FIGURE 18. The regressions plots. 


\begin{tabular}{|c|c|c|c|c|c|c|}
\hline \multirow{2}{*}{$\begin{array}{l}\text { Experimental } \\
\text { trials }\end{array}$} & \multicolumn{3}{|c|}{ Actual values } & \multicolumn{3}{|c|}{ Predicted values } \\
\hline & $\begin{array}{c}\text { Surface } \\
\text { Roughness } \\
(\mu \mathrm{m})\end{array}$ & $\begin{array}{c}\text { Temp. } \\
\left({ }^{\circ} \mathrm{C}\right)\end{array}$ & $\begin{array}{c}\text { Surface } \\
\text { Roughness } \\
(\mu \mathrm{m}) \\
(\mathrm{RSM})\end{array}$ & $\begin{array}{c}\text { Surface } \\
\text { Roughness } \\
(\mu \mathrm{m}) \\
(\mathrm{ANN})\end{array}$ & $\begin{array}{c}\text { Temp. } \\
\left({ }^{\circ} \mathrm{C}\right) \\
(\mathrm{RSM})\end{array}$ & $\begin{array}{c}\text { Temp. } \\
\left({ }^{\circ} \mathrm{C}\right) \\
(\mathrm{ANN})\end{array}$ \\
\hline 1. & 0.79 & 176 & 0.7867 & 0.7901 & 177.345 & 176.011 \\
\hline 2. & 0.91 & 160 & 0.8765 & 0.9101 & 161.654 & 160.505 \\
\hline 3. & 0.86 & 85 & 0.9786 & 0.8599 & 84.235 & 85.045 \\
\hline 4. & 0.98 & 165 & 0.9999 & 0.9802 & 164.234 & 165.234 \\
\hline 5. & 0.75 & 124 & 0.7768 & 0.7501 & 126.786 & 123.999 \\
\hline 6. & 0.78 & 140 & 0.7576 & 0.7802 & 142.348 & 139.999 \\
\hline 7. & 0.83 & 170 & 0.8478 & 0.8300 & 168.345 & 170.001 \\
\hline 8. & 0.88 & 156 & 0.8945 & 0.8800 & 157.097 & 156.201 \\
\hline 9. & 0.84 & 145 & 0.8678 & 0.8465 & 145.906 & 145.332 \\
\hline 10. & 0.70 & 157 & 0.7234 & 0.7000 & 154.55 & 157.001 \\
\hline 11. & 0.79 & 95 & 0.7809 & 0.7930 & 96.546 & 94.999 \\
\hline 12. & 0.88 & 93 & 0.8903 & 0.8801 & 93.997 & 92.999 \\
\hline 13. & 0.84 & 87 & 0.8568 & 0.8400 & 86.435 & 86.999 \\
\hline 14. & 0.52 & 88 & 0.5457 & 0.5200 & 88.094 & 88.001 \\
\hline 15. & 0.60 & 60 & 0.6216 & 0.6002 & 60.987 & 60.002 \\
\hline 16. & 0.96 & 100 & 0.9778 & 0.9600 & 100.778 & 100.002 \\
\hline 17. & 0.67 & 120 & 0.6670 & 0.6701 & 121.983 & 120.001 \\
\hline 18. & 0.98 & 180 & 0.9902 & 0.9980 & 180.995 & 179.001 \\
\hline 19. & 0.99 & 165 & 0.9763 & 0.9900 & 165.679 & 164.999 \\
\hline 20. & 0.58 & 158 & 0.5567 & 0.5867 & 156.547 & 157.999 \\
\hline 21. & 0.56 & 177 & 0.5347 & 0.5600 & 177.985 & 176.999 \\
\hline 22 . & 0.74 & 186 & 0.7560 & 0.7400 & 185.856 & 186.001 \\
\hline 23. & 0.77 & 168 & 0.7479 & 0.7765 & 169.753 & 168.002 \\
\hline 24. & 0.86 & 175 & 0.8906 & 0.8679 & 176.779 & 175.002 \\
\hline 25 . & 0.85 & 145 & 0.8237 & 0.8599 & 145.908 & 145.001 \\
\hline 26. & 0.79 & 123 & 0.7779 & 0.7923 & 122.764 & 122.999 \\
\hline 27. & 0.88 & 127 & 0.8673 & 0.8600 & 125.667 & 126.999 \\
\hline 28. & 0.46 & 180 & 0.4237 & 0.4500 & 181.458 & 179.999 \\
\hline 29. & 0.66 & 87 & 0.6679 & 0.6607 & 87.975 & 86.999 \\
\hline 30. & 0.80 & 78 & 0.8963 & 0.8325 & 78.875 & 78.001 \\
\hline 31. & 0.87 & 98 & 0.8346 & 0.8678 & 96.775 & 98.001 \\
\hline 32. & 0.76 & 96 & 0.78429 & 0.7700 & 95.789 & 96.002 \\
\hline 33. & 0.95 & 92 & 0.9974 & 0.9450 & 93.446 & 92.002 \\
\hline 34. & 0.79 & 102 & 0.7642 & 0.7900 & 102.998 & 101.999 \\
\hline 35. & 0.98 & 105 & 0.9458 & 0.9804 & 106.765 & 105.999 \\
\hline 36. & 0.78 & 125 & 0.7648 & 0.7867 & 123.457 & 125.999 \\
\hline 37. & 0.80 & 136 & 0.7998 & 0.8002 & 137.896 & 136.222 \\
\hline 38. & 0.87 & 140 & 0.7998 & 0.87001 & 142.556 & 140.001 \\
\hline 39. & 0.58 & 155 & 0.5679 & 0.58001 & 156.798 & 155.001 \\
\hline 40. & 0.77 & 160 & 0.7942 & 0.77001 & 163.564 & 160.011 \\
\hline 41. & 0.54 & 156 & 0.5679 & 0.54001 & 156.789 & 156.011 \\
\hline
\end{tabular}

TABLE 9. The results obtained from both the physical and numerical experiments. 


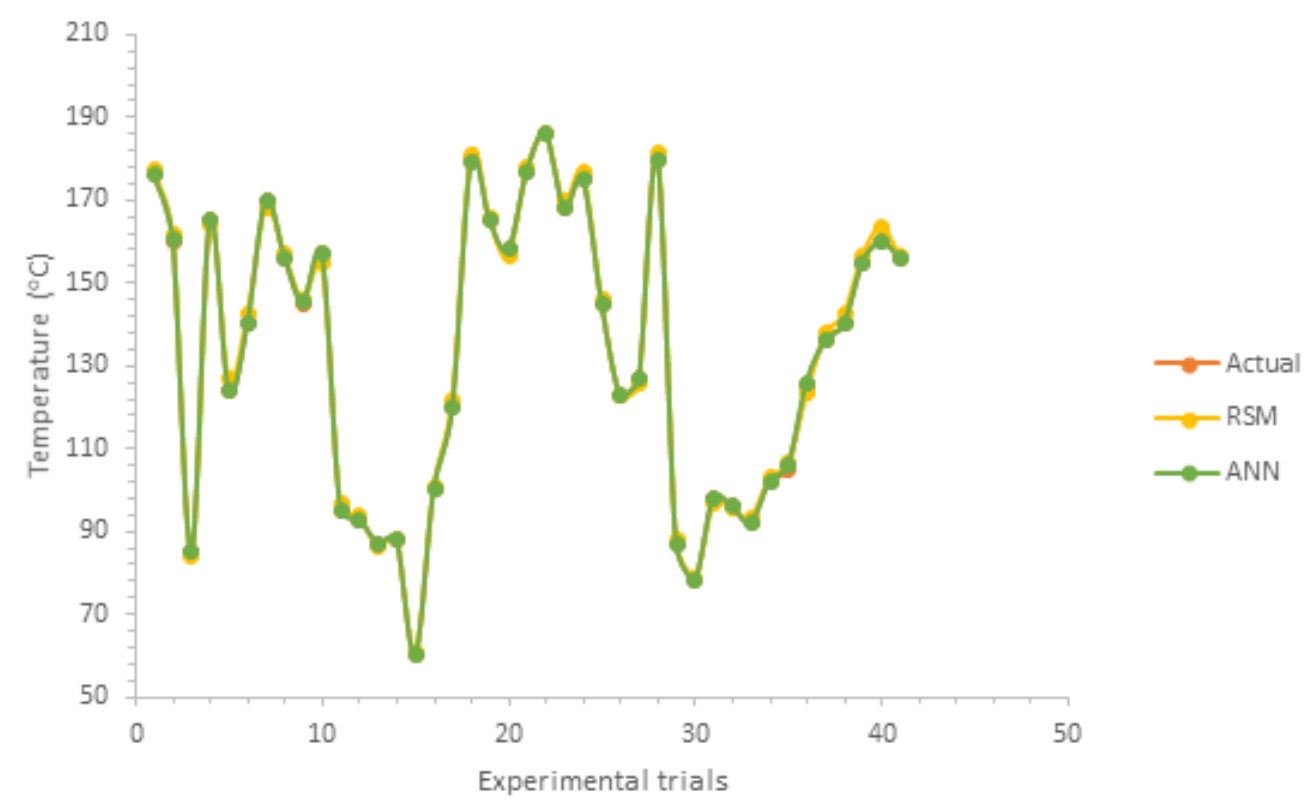

Figure 19. Actual and predicted values for temperature.

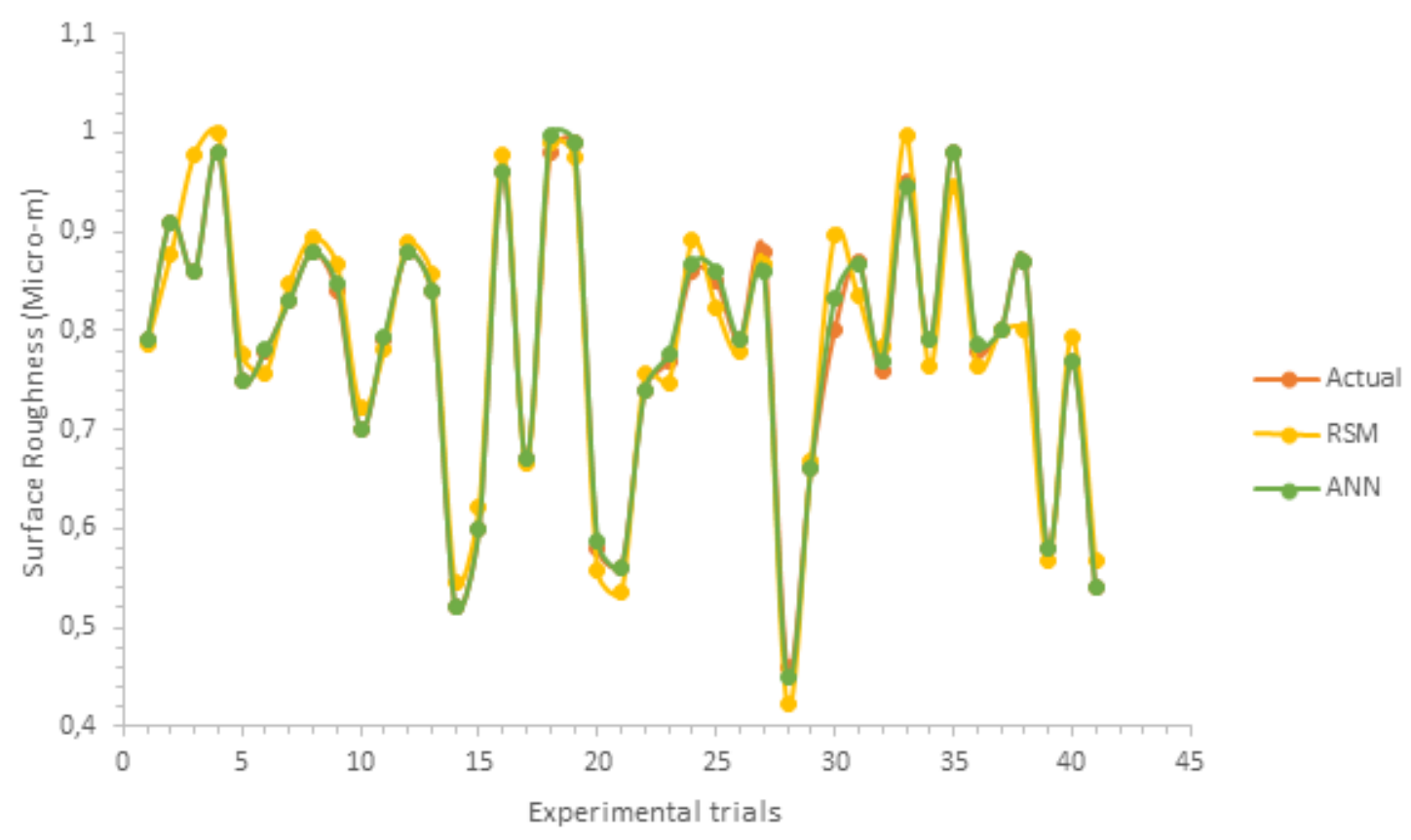

Figure 20. Actual and predicted values for surface roug. 


\section{Conclusion}

The prediction of the temperature and surface roughness during the milling operation of Ti6Al4V was successfully carried out using the RSM and ANN. The developed RSM and ANN models were highly efficient for a predictive purpose as their correlation coefficients $\mathrm{R}$ were close to 1 . This indicates that there exists a linear relationship between the outputs and targets, thus, indicating the significance of the overall model terms and an agreement between the values of the temperature and surface roughness obtained from both the physical and numerical experimentations. The RSM demonstrated a good predictive ability with the predicted values found to be within the range of the actual values. The ANOVA of the models developed using the RSM were found to be statistically significant, which implies the suitability of the models for correlative and predictive purposes. However, the predicted values from the ANN were observed to be closer to the actual experimental values, for both the temperature and the surface roughness, than the predicted values from the RSM models. Nonetheless, the errors generated by both approaches were negligible and found to be within the permissible limit. This work can find application in the production and manufacturing industries especially for process control, optimization and monitoring of cutting temperature and surface roughness in order to keep them within the permissible limit. Further work can consider the use of Genetic Algorithm or other analytical models as well as comparative analyses among the identified approaches.

\section{REFERENCES}

[1] M. B. Mhamdi, M. Boujelbene, E. Bayraktar, A. Zghal. Surface integrity of titanium alloy Ti-6Al-4V in ball end milling. Physics Procedia 25:355 - 362, 2012. DOI:10.1016/j.phpro.2012.03.096

[2] A. Koohestani, J. Mo, S. Yang. Stability prediction of titanium milling with data driven reconstruction of phase-space. Machining Science and Technology 18(1):78 - 98, 2014. DOI:10.1080/10910344.2014.863638

[3] P. J. Arrazola, A. Garay, L. M. Iriarte, et al. Machinability of titanium alloys (Ti6Al4V and Ti555.3). Journal of Materials Processing Technology 209(5):2223 - 2230, 2009. DOI:10.1016/j.jmatprotec.2008.06.020.

[4] S. E. Haghighi, H. B. Lu, G. Y. Jian, et al. Effect of $\alpha$ " martensite on the microstructure and mechanical properties of beta-type Ti-Fe-Ta alloys. Materials $\&$ Design 76:47 - 54, 2015. DOI:10.1016/j.matdes.2015.03.028

[5] S. Ehtemam-Haghighi, Y. Liu, G. Cao, L.-C. Zhang. Influence of $\mathrm{Nb}$ on the $\beta \rightarrow \alpha$ " martensitic phase transformation and properties of the newly designed Ti-Fe-Nb alloys. Materials Science and Engineering: $C$ 60:503 - 510, 2016. DOI:10.1016/j.msec.2015.11.072.

[6] N. Taniguchi, S. Fujibayashi, M. Takemoto, et al. Effect of pore size on bone ingrowth into porous titanium implants fabricated by additive manufacturing: An in vivo experiment. Materials Science and Engineering: $C$ 59:690 - 701, 2016. DOI:10.1016/j.msec.2015.10.069.

[7] G. Quintana, J. Ciurana. Chatter in machining processes: A review. International Journal of Machine Tools and Manufacture 51(5):363 - 376, 2011. DOI:10.1016/j.ijmachtools.2011.01.001.

[8] C. Bandapalli, K. K. Singh, B. M. Sutaria, D. V. Bhatt. Experimental investigation of top burr formation in high-speed micro-end milling of titanium alloy. Machining Science and Technology 22(6):989 1011, 2018. DOI:10.1080/10910344.2018.1449213

[9] M. Benedetti, M. Cazzolli, V. Fontanari, M. Leoni. Fatigue limit of Ti6Al4V alloy produced by selective laser sintering. Procedia Structural Integrity 2:3158 3167, 2016. DOI:10.1016/j.prostr.2016.06.394

[10] U. S. Dixit, S. N. Joshi, J. P. Davim. Incorporation of material behavior in modeling of metal forming and machining processes: A review. Materials $\&$ Design 32(7):3655 - 3670, 2011. DOI:10.1016/j.matdes.2011.03.049

[11] F. Kara, K. Aslantaş, A. Çiçek. Prediction of cutting temperature in orthogonal machining of AISI 316L using artificial neural network. Applied Soft Computing 38:64 - 74, 2016. DOI:10.1016/j.asoc.2015.09.034.

[12] C. H. Lauro, L. C. Brandão, S. L. Ribeiro Filho. Monitoring the temperature of the milling process using infrared camera. Scientific research and essays 8(23):1112 - 1120, 2013. DOI:10.5897/SRE12.579

[13] G. Le Coz, M. Marinescu, A. Devillez, et al. Measuring temperature of rotating cutting tools: Application to MQL drilling and dry milling of aerospace alloys. Applied Thermal Engineering 36:434 441, 2012. DOI:10.1016/j.applthermaleng.2011.10.060.

[14] J. Chen, K. Chandrashekhara, C. Mahimkar, et al. Void closure prediction in cold rolling using finite element analysis and neural network. Journal of Materials Processing Technology 211(2):245 - 255, 2011. DOI:10.1016/j.jmatprotec.2010.09.016.

[15] A. Molinari, R. Cheriguene, H. Miguelez. Numerical and analytical modeling of orthogonal cutting: The link between local variables and global contact characteristics. International Journal of Mechanical Sciences 53(3):183 - 206, 2011. DOI:10.1016/j.ijmecsci.2010.12.007.

[16] L. M. Maiyar, R. Ramanujam, K. Venkatesan, J. Jerald. Optimization of machining parameters for end milling of inconel 718 super alloy using taguchi based grey relational analysis. Procedia Engineering 64:1276 - 1282, 2013. DOI:10.1016/j.proeng.2013.09.208

[17] A. M. Ravi, S. M. Murigendrappa, P. G. Mukunda. Experimental investigation on thermally enhanced machining of high-chrome white cast iron and to study its machinability characteristics using Taguchi method and artificial neural network. The International Journal of Advanced Manufacturing Technology 72:1439 - 1454, 2014. DOI:10.1007/s00170-014-5752-4

[18] T. D. B. Kannan, G. R. kannan, B. S. Kumar, N. Baskar. Application of artificial neural network modeling for machining parameters optimization in drilling operation. Procedia Materials Science 5:2242 2249, 2014. DOI:10.1016/j.mspro.2014.07.433 
[19] U. Natarajan, P. R. Periyanan, S. H. Yang. Multipleresponse optimization for micro-endmilling process using response surface methodology. International Journal of Advanced Manufacturing Technology 56(1):177 - 185, 2011. DOI:10.1007/s00170-011-3156-2

[20] I. A. Daniyan, I. Tlhabadira, S. N. Phokobye, et al. Modelling and optimization of the cutting forces during ti6al4v milling process using the response surface methodology and dynamometer. MM Science Journal 2019:3353 - 3363, 2019.

DOI:10.17973/MMSJ.2019_11_2019093

[21] R. Saidi, B. Ben Fathallah, T. Mabrouki, et al. Modeling and optimization of the turning parameters of cobalt alloy (Stellite 6) based on RSM and desirability function. The International Journal of Advanced Manufacturing Technology 100:2945 - 2968, 2019. DOI:10.1007/s00170-018-2816-x

[22] Y. Xu, Q. Zhang, W. Zhang, P. Zhang. Optimization of injection molding process parameters to improve the mechanical performance of polymer product against impact. The International Journal of Advanced Manufacturing Technology 76:2199 - 2208, 2014. DOI:10.1007/s00170-014-6434-y

[23] S. Kashyap, D. Datta. Process parameter optimization of plastic injection molding: a review. International Journal of Plastics Technology 19:1 - 18, 2015. DOI:10.1007/s12588-015-9115-2

[24] M. Mahdavi Jafari, S. Soroushian, G. R. Khayati. Hardness optimization for Al6061-MWCNT nanocomposite prepared by mechanical alloying using artificial neural networks and genetic algorithm. Journal of Ultrafine Grained and Nanostructured Materials 50(1):23 - 32, 2017. DOI:10.7508/jufgnsm.2017.01.04.

[25] S. Altarazi, M. Ammouri, A. Hijazi. Artificial neural network modeling to evaluate polyvinylchloride composites' properties. Computational Materials Science 153:1 - 9, 2018. DOI:10.1016/j.commatsci.2018.06.003.

[26] I. Tlhabadira, I. A. Daniyan, R. Machaka, et al. Modelling and optimization of surface roughness during AISI P20 milling process using Taguchi method. The International Journal of Advanced Manufacturing Technology 102:3707 - 3718, 2019. DOI:10.1007/s00170-019-03452-4.

[27] G. Kant, K. S. Sangwan. Predictive modelling and optimization of machining parameters to minimize surface roughness using artificial neural network coupled with genetic algorithm. Procedia CIRP 31:453458, 2015. DOI:/10.1016/j.procir.2015.03.043

[28] P. Kovac, D. Rodic, V. Pucovsky, et al. Application of fuzzy logic and regression analysis for modeling surface roughness in face milliing. Journal of Intelligent Manufacturing 24:755, 2012. DOI:10.1007/s10845-012-0623-z

[29] G. Campatelli, L. Lorenzini, A. Scippa. Optimization of process parameters using a response surface method for minimizing power consumption in the milling of carbon steel. Journal of Cleaner Production 66:309 316, 2014. DOI:10.1016/j.jclepro.2013.10.025

[30] F. Djavanroodi, B. Omranpour, M. Sedighi. Artificial neural network modeling of ECAP process. Materials and Manufacturing Processes 28(3):276 - 281, 2013. DOI:10.1080/10426914.2012.667889
[31] B. Ben Fathallah, R. Saidi, C. Dakhli, et al. Mathematical modelling and optimization of surface quality and productivity in turning process of aisi 12114 free-cutting steel. International Journal of Industrial Engineering Computations 10(4):557 - 576, 2019. DOI:10.5267/j.ijiec.2019.3.001

[32] U.S. Titanium Industry Inc. Titanium Alloys Ti6Al4V Grade 5. AzoM. https: //www. azom. com/article.aspx?ArticleID=1547, 2017. Accessed: 2 July 2019.

[33] I. A. Daniyan, I. Thabadira, O. O. Daramola, et al. Measurement and optimization of cutting forces during M200 TS milling process using the response surface methodology and dynamometer. Procedia CIRP 88:288 - 293, 2020. DOI:10.1016/j.procir.2020.05.050

[34] I. Daniyan, F. Fameso, F. Ale, et al. Modelling, simulation and experimental validation of the milling operation of titanium alloy (Ti6Al4V). The

International Journal of Advanced Manufacturing Technology 109(7):1853 - 1866, 2020. DOI:10.1007/s00170-020-05714-y

[35] V. Aggarwal, S. S. Khangura, R. Garg. Parametric modeling and optimization for wire electrical discharge machining of Inconel 718 using response surface methodology. The International Journal of Advanced Manufacturing Technology 79:31 - 47, 2015. DOI:10.1007/s00170-015-6797-8.

[36] M. Gayatri Vineela, A. Dave, P. Kiran Chaganti. Artificial neural network based prediction of tensile strength of hybrid composites. Materials Today: Proceedings 5(9, Part 3):19908 - 19915, 2018. DOI:10.1016/j.matpr.2018.06.356.

[37] I. A. Daniyan, I. Thlabadira, S. Phokobye, et al. Modelling and optimization of the cutting parameters for the milling operation of titanium alloy (Ti6Al4V). In IEEE 11th International Conference on Mechanical and Intelligent Manufacturing Technologies (ICMIMT 2020), pp. 68 - 73. 2020. DOI:10.1109/ICMIMT49010.2020.9041193.

[38] N. S. Kumar, A. Shetty, A. Shetty, et al. Effect of spindle speed and feed rate on surface roughness of carbon steels in CNC turning. Procedia Engineering 38:691 - 697, 2012. DOI:10.1016/j.proeng.2012.06.087

[39] I. A. Daniyan, I. Thabadira, O. O. Daramola, K. Mpofu. Design and optimization of machining parameters for effective AISI P20 removal rate during milling operation. Procedia CIRP 84:861 - 867, 2019. DOI:10.1016/j.procir.2019.04.301

[40] S. N. Phokobye, I. A. Daniyan, I. Thabadira, et al. Model design and optimization of carbide milling cutter for milling operation of M200 tool steel. Procedia CIRP 84:954 - 959, 2019. DOI:10.1016/j.procir.2019.04.300. 